\title{
Wireless Technologies for IoT in Smart Cities
}

\author{
Laura García $^{1}$, Jose M. Jiménez ${ }^{1}$, Miran Taha ${ }^{1,2}$, Jaime Lloret $^{1}$ \\ ${ }^{1}$ Integrated Management Coastal Research Institute, Universitat Politècnica de València. \\ C/ Paranimf nº 1, Grao de Gandía - Gandía, Valencia, Spain \\ ${ }^{2}$ Department of Computer Science, University of Sulaimani. \\ Tasluja Street, n 1, 46001, Kurdistan region, Iraq \\ E-mail: laugarg2@teleco.upv.es, jojiher@dcom.upv.es,miab2@doctor.upv.es, \\ jlloret@dcom.upv.es
}

Received: January 9, 2018

Accepted: March 28, 2018

Published: March 31, 2018

DOI: 10.5296/npa.v10i1.12798

URL: https:// doi.org/10.5296/npa.v10i1.12798

\begin{abstract}
As cities continue to grow, numerous initiatives for Smart Cities are being conducted. The concept of Smart City encompasses several concepts being governance, economy, management, infrastructure, technology and people. This means that a Smart City can have different communication needs. Wireless technologies such as WiFi, ZigBee, Bluetooth, WiMax, 4G or LTE (Long Term Evolution) have presented themselves as solutions to the communication needs of Smart City initiatives. However, as most of them employ unlicensed bands, interference and coexistence problems are increasing. In this paper, the wireless technologies available nowadays for IoT (Internet of Things) in Smart Cities are presented. Our contribution is a review of wireless technologies, their comparison and the problems that difficult coexistence among them. In order to do so, the characteristics and adequacy of wireless technologies to each domain are considered. The problems derived of over-crowded unlicensed spectrum and coexistence difficulties among each technology are discussed as well. Finally, power consumption concerns are addressed.
\end{abstract}

Keywords: Smart City, wireless; coexistence, energy consumption, monitoring, Internet of Things (IoT). 


\section{Introduction}

At present, it is fairly difficult to find a uniform definition of the concept of Smart City. In fact, there are studies entirely dedicated to defining this concept [1]. Among the available definitions of Smart City, the European Commission defines it as "cities which best use modern, integrated technology services and infrastructure in energy, transport and ICT to respond to the social and economic needs of society" [2]. Other definitions also address the urban development of the city, improving Quality of Life (QoL), natural resources management, optimizing efficiency and effectiveness, the concept of a smart city being a system, and people's participation [3]. Moreover, new Smart City projects are being developed as governments promote their deployment in order to increase the performance of cities in different aspects. The European Union 2020 strategy focuses on smart growth in education, research and innovation, sustainable growth, promoting sustainable energy resources, and inclusive growth, fighting poverty and creating jobs. These principles are being applied to smart cities all over the world in order to improve the life of its citizens.

As the initiatives taken to turn a city into a smart city may be varied and have different requirements, employing one unified technology throughout the city may not be efficient. Although wired solutions present a reliable channel to transmit data, the cost of deploying a wired network that connects all devices is extremely high and the result would be considerably inefficient. Wireless technologies have presented themselves as a solution to the rapid growth of devices that are connected to the network as well as the increasing demand of services that allow monitoring cities. IoT is gaining rapid popularity and it is being utilized for transport, health, environment, animal monitoring and smart metering applications $[4,5]$. Wireless Sensor Networks (WSN) are being employed all over the world as a low-cost and low-energy consuming method to provide a communication mechanism [6]. However, wireless technologies are varied and their utilization should be considered depending on the application. Traffic type, distance, energy consumption or number of nodes are some of the factors that should be considered when deciding how to transmit the gathered data. Moreover, the abuse of wireless technologies may derive in some problems.

The majority of the wireless technologies available nowadays employ the $2.4 \mathrm{GHz}$ ISM (Industrial, Scientific and Medical) band. It has not been a great problem until wireless devices started growing at a fast pace. Cable connections between computers and peripherals are being replaced by technologies such as Bluetooth [7]. It is also being employed by home automation systems or telemedicine applications [8]. ZigBee is popular for monitoring systems where a great number of nodes and low energy consumption are required. Services that require interaction with humans are usually utilized with PCs, smartphones or tablets, such as Ambient Assisted Living (AAL) and healthcare systems, and employ WiFi or mobile communications $[9,10]$. Rural areas are usually connected through WiMax as it provides a wireless communication for longer distances. As a result, the $2.4 \mathrm{GHz}$ ISM band is overcrowded and interferences caused by different wireless technologies are increasing. That implies higher packet loss and low performance.

The need of choosing correctly the best technology for a particular application is evident. 
Depending on the reliability needs of the system, utilizing technologies that operate on unlicensed frequency bands may compromise its performance. Selecting the technologies that less interfere with each other can help in assuring the correct deployment and function of Smart Cities.

Employing the aforementioned reasons as motivation, in this paper, we determine the main aspects that are part of a smart city. Furthermore, the evolution of wireless technologies and their characteristics is detailed. Then, the overcrowded $2.4 \mathrm{GHz}$ ISM band and the coexistence problems among wireless technologies are discussed. Finally, the differences in power consumption are reviewed. Moreover, the current Smart City projects and the wireless technology employed for each domain is also discussed.

The rest of the paper is organized as follows. The main elements of a smart city are presented in section 2. Section 3 presents the description of the wireless technologies available nowadays and their evolution. The discussion of the characteristics of each technology, coexistence problems and power consumption are presented in section 4. Lastly, our conclusion and future work are considered in section.

\section{Domains of a Smart City}

Smart Cities encompass varied aspects of the correct functioning and management of a city. However, the aspects considered in literature are not always the same. As a result, the discussion on which domains are part of a Smart City is opened. In this section, the most common domains of a smart city, referred in literature, will be described.

Governance: This factor focuses on digitalizing the administration to improve efficiency, incorporating e-democracy by improving the voting system and providing citizens to an easy access to public documents, which can improve transparency, as described by Paolo Neirotti et al. in [11]. Suha Alawadhi et al. discuss in [12] that urban planning can be included in this section, allowing the smart growth of the city considering factors such as air pollution, managing public facilities cost, school overcrowding, open spaces and traffic congestions.

Economy: Paolo Neirotti et al. [11] also comment on the economic domain of a Smart City. It consists of incorporating innovative solutions to improve the economy and business opportunities of the city. Using technology to develop the area and increase job opportunities have also been initiatives taken by smart cities. The economic expansion of a city attracts human capital and allows investing the financial resources on improving other aspects of the city.

Management: This domain encompasses transport, energy and natural resources management, as explained by Mahmoud Al-Hader et al. in [13]. It is one of the most developed factors among smart cities. IoT and Wireless Sensor Network (WSN) solutions are the technologies that are currently being employed to obtain data and manage resources and traffic allocation. Managing crop cultivation [14], feed dosing and produce development for farms, allocating and measuring the water throughput for agriculture [15], municipal and 
domestic purposes, controlling public lighting, energy demand and renewable energies, improving city logistics and public transport are examples of initiatives that are being performed nowadays.

Infrastructures: Paolo Neirotti et al. [11] also discuss this domain as part of the aspects of a Smart City. Quality of Living (QoL) aspects such as lighting, heating or ventilation are part of this category. Facility management such as property, leasing and services such as cleaning and maintenance are also included. Controlling energy and water consumption within the building, telecommunications and elevators are also some of the solutions that can be performed in a smart city.

Technology: The technology factor is often considered although it can be part of the solutions developed for the other factors. It consists of employing technology to develop new solutions in order to achieve an intelligent, digital and virtual city, as indicated by Taewoo Nam et al. in [16]. This means utilizing the available technology to improve how the city functions and improve the satisfaction of its citizens.

People: This domain is discussed by Paolo Neirotti et al. [11] as well as Taewoo Nam et al. [16]. Entertainment, public safety, improving the services provided by the healthcare system, cultural activities, managing welfare and the maintenance of public spaces as well as new ways of using technology to improve the education system are examples of the possible solutions encompassed in this factor. One of the motivations of smart cities are improving the QoL of citizens and making their life easier. After all, the purpose of all the other factors is to aid human beings.

It is important to identify the domain where wireless technologies are to be deployed, as the conditions of the environment and the parameters to be measured change depending on it. For example, farm management solutions may need technologies that allow long-distance communications while education solutions may require shorter ranges and higher bandwidths. Fig. 1 summarizes the six dimensions of a Smart City with examples of applications.

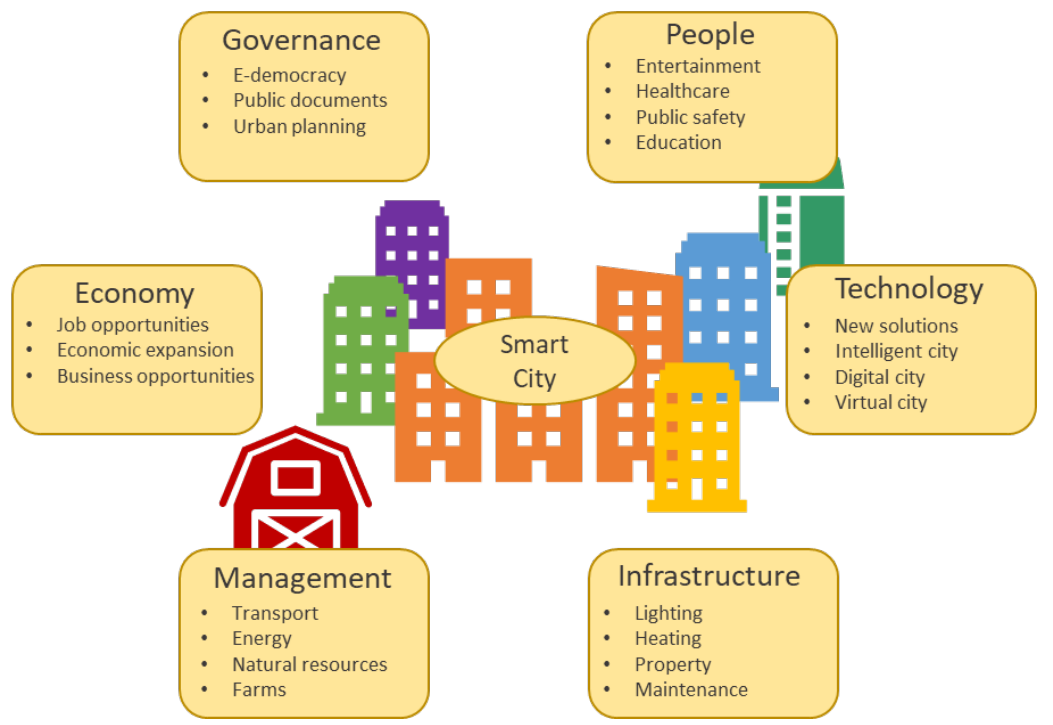

Figure 1. Dimensions of a Smart City. 


\section{Evolution of wireless technologies}

Wireless technologies have been developed throughout many years in order to be able to connect millions of devices. Depending on the distance, transmission rate or power consumption requirements, differentiated solutions were proposed. Currently, whether standardized or not, the available technologies allow us to connect a great number of devices and exchange information on energy, water or traffic management being part of all the domains of a Smart City. In this section, the technologies used nowadays to implement a smart city are detailed.

\subsection{IEEE 802.11 Wireless Standards}

In this subsection, the standards of IEEE 802.11 wireless technologies are going to be described.

The working group active and responsible for writing standards for wireless local area networks (LANs) is called 802.11 [17]. This working group operates in accordance with the standards of the IEEE Computer Society [18], IEEE-SA Standards Board [19] and the IEEE LMSC "LAN / MAN Standards Committee" also named as "802" [20].

The work developed in 802.11 is carried out in the following phases: a study group is created that is in responsible for studying the possible viability, marketability and that poses the initial requirements to propose it to a new group of tasks, a group of tasks was created to each standard approved or when a change occurs, and there are also different standing committee's that are responsible for monitoring the work.

IEEE 802.11 networks can perform as two different modes, as infrastructure networks and ad-hoc networks. In the infrastructure mode of operation, the wireless network is divided into cells. An access point (AP) or a base station, which is considered as the controller, provide service to each cell. Depending on the environment and its location, each access point will have a different coverage range. The Ad-Hoc mode is created by joining devices without an access point to control access to the network.

Because of the flexibility and the performance it provides, the IEEE 802.11 standard is increasingly employed in both temporary and permanent local area network installations. In addition, using devices that meet the standard allows us to make changes without rewiring the network, which reports significant savings. The standard is usually present in devices such as laptops, telephones, tablets, network infrastructure, home appliances, consumer electronics or healthcare devices, among others. They are often used for accessing broadband networks, providing access to public places, sensor networks, etc.

Typically, IEEE 802.11 operates in the ISM frequency band and uses unlicensed spectrum bands except for IEEE 802.11y (light licensing) and for IEEE 802.11af (TV whitespace). IEEE 802.11 has a variety of standards, each represented with a letter suffix such as IEEE 802.11a, IEEE 802.11b, IEEE 802.11g, and so on. Through these, wireless standards, rules on safety issues and quality of service are detailed. In the following sections, the principal of the IEEE 802.11 standards will be described. 


\subsubsection{IEEE 802.11a}

It was ratified in 1999 at the same time as IEEE 802.11b, but they are not interoperable, except with the equipment that works in dual band.

The main advantage of the IEEE 802.11a standard is that, working in the $5 \mathrm{GHz}$ band, it has less interference levels than other devices. This means that it has a high level of performance, but it also means that the chips for this standard are more expensive. Operating in the $5 \mathrm{GHz}$ band has higher propagation losses than operating in the $2.4 \mathrm{GHz}$ band. Its main characteristics are shown in Table 1.

Table 1. Main characteristics of IEEE 802.11a.

\begin{tabular}{|c|l|}
\hline Characteristics & Values \\
\hline \hline Date standar approval & 1999 \\
\hline Maximun data rate (Mbps) & 54 \\
\hline Typical data rate (Mbps) & 25 \\
\hline Typical range indoors (Metres) & 35 \\
\hline Typical range outdoors (Metres) & 119 \\
\hline RF Band (GHz) & 5 \\
\hline Number of spatial streams & 1 \\
\hline Channel with (MHz) & 20 \\
\hline Modulation & OFDM \\
\hline
\end{tabular}

It has 16 non-overlapping channels. According to their regulatory domains in America and most other countries, they have 8 channels, however, in Europe, the Middle East and Africa (EMEA), Israel and Japan, there are 4 available channels.

According to the standard, they can achieve a theoretical transfer rate of 54Mbps. However, the raw data rate can be reduced to 48 Mbps, 36 Mbps, 24 Mbps, 18 Mbps, 12 Mbps, $9 \mathrm{Mbps}$ and $6 \mathrm{Mbps}$ if it is required. It uses orthogonal frequency division multiplexing (OFDM) with 52 subcarriers, 48 of which are utilized for data transmission and 4 are pilotsubcarriers. The $20 \mathrm{MHz}$ bandwidth is divided by 64, which provides a separation between individual subcarriers of $0.3125 \mathrm{MHz}$.

For each set of data rate, a different modulation form is used. The most used modulations are Binary Phase Shift Keying (BPSK), Quadrature Phase Shift Keying (QPSK), Quadrature Amplitude Modulation (QAM), Direct Sequence Spread Spectrum (DSSS), Complementary code keying (CKK) and OFDM. The duration of each symbol is 4 microseconds, and there is a protection interval of 0.8 microseconds in the signal itself. Table 2 shows the different forms of modulation. 
Table 2. Modulations of IEEE 802.11a.

\begin{tabular}{|c|c|}
\hline Data Rate (Mbps) & Modulation \\
\hline $\mathbf{6}$ & BPSK \\
\hline $\mathbf{9}$ & BPSK \\
\hline $\mathbf{1 2}$ & QPSK \\
\hline $\mathbf{1 8}$ & QPSK \\
\hline $\mathbf{2 4}$ & 16 QAM \\
\hline $\mathbf{3 6}$ & 16 QAM \\
\hline $\mathbf{4 8}$ & 64 QAM \\
\hline $\mathbf{5 4}$ & 64 QAM \\
\hline
\end{tabular}

\subsubsection{IEEE 802.11b}

As mentioned in the previous section, this standard was ratified in 1999 alongside IEEE 802.11a. However, they can only be interoperable in dual band equipment.

As it works in the $2.4 \mathrm{GHz}$ band, there are interference problems with the many other standards that operate in this band. Moreover, every day more and more technologies that employ the $2.4 \mathrm{GHz}$ band appear, which can be the cause some functioning difficulties. However, it allows greater reach and greater capacity to traverse obstacles than the $5 \mathrm{GHz}$ band. Its main characteristics are shown in Table 3.

Table 3. Main characteristics of IEEE 802.11b.

\begin{tabular}{|c|c|}
\hline Characteristics & Values \\
\hline \hline Date standar approval & 1999 \\
\hline Maximun data rate (Mbps) & 11 \\
\hline Typical data rate (Mbps) & 5,9 \\
\hline Typical range indoors (Metres) & 35 \\
\hline Typical range outdoors (Metres) & 140 \\
\hline RF Band (GHz) & 2,4 \\
\hline Channel with (MHz) & 20 \\
\hline Modulation & CCK (DSSS) \\
\hline
\end{tabular}

It has 14 non-overlapping channels. However, according to their regulatory domains in America and most other countries, they have 11 channels. Furthermore, in EMEA there are available 13 channels, in Israel 7 channels and in Japan 14 channels.

This specification uses CDMA / DSSS (Code Division Multiple Access / Direct Sequence Spread Spectrum) as the original IEEE 802.11 standard. As a consequence, upgrading the existing chipsets in order to be able to implement the new 802.11b standard was fairly easy.

IEEE 802.11b devices can reach a theoretical data rate of $11 \mathrm{Mbps}$, but if the interferences increase or the signal power is diminished, inferior transmission speeds are adopted to be able 
to minimize the error rate. The transmission speeds will gradually decrease to $5.5 \mathrm{Mbps}, 2$ Mbps, and 1 Mbps. This functionality is called Adaptive Rate Selection (ARS).

Although the theoretical transmission rate is $11 \mathrm{Mbps}$, the real transmission rate is approximately 5.9 Mbps, due, among other factors, to the use of CSMA / CA. If UDP is used, instead of TCP, the data rate can increase up to 7.1 Mbps.

\subsubsection{IEEE 802.11g}

This standard was ratified in 2003 as the evolution of the standard IEEE 802.11b. Devices that meet the standard are compatible with those that comply with IEEE 802.11b. Its main characteristics are shown in Table 4.

Table 4. Main characteristics of IEEE 802.11g.

\begin{tabular}{|c|c|}
\hline Characteristics & Values \\
\hline \hline Date standard approval & 2003 \\
\hline Maximum data rate (Mbps) & 54 \\
\hline Typical data rate (Mbps) & 24 \\
\hline Typical range indoors (Meters) & 45 \\
\hline Typical range outdoors (Meters) & 90 \\
\hline RF Band (GHz) & 2,4 \\
\hline Channel with (MHz) & 22 \\
\hline Modulation & OFDM, DSSS and CCK \\
\hline
\end{tabular}

It has 14 non-overlapping channels. 11 channels according to their regulatory domains in America and most other countries, and 13 channels in EMEA. The channels that are generally used with the 802.11g and the IEEE 802.11b standard are 1, 6 and 11 in America and most other countries, and 1, 4, 9 and 13, in EMEA.

Although the theoretical transmission rate is $54 \mathrm{Mbps}$, the real transmission rate is approximately 24 Mbps. Moreover, if an IEEE 802.11b-compliant device is introduced into an IEEE 802.11g network, the speed is significantly reduced, to accommodate IEEE 802.11b transmission rates each time that device participates in the transmission. Table 5 shows the different forms of modulation.

Table 5. Modulations of IEEE 802.11g.

\begin{tabular}{|c|c|}
\hline Data Rate (Mbps) & Modulation \\
\hline $1,2,5,5,11$ & DSSS-CCK \\
\hline $6,9,12,18,24,36,48,54$ & OFDM \\
\hline $1,2,5.5,11,22,33$ & DSSS/PBCC \\
\hline $6,9,12,18,24,36,48,54$ & DSSS-OFDM \\
\hline
\end{tabular}

\subsubsection{IEEE 802.11n}

This standard was ratified in 2009 as a new standard. It is the result of the creation of a working group to increase the data rates provided by the previous IEEE 802.11a, IEEE 802.11b and IEEE 802.11g. Its main characteristics are shown in Table 6. 
Table 6. Main characteristics of IEEE 802.11n.

\begin{tabular}{|c|c|}
\hline Characteristics & values \\
\hline \hline Date standar approval & 2009 \\
\hline Maximun data rate (Mbps) & 600 \\
\hline Typical range indoors (Metres) & 70 \\
\hline Typical range outdoors (Metres) & 250 \\
\hline RF Band (GHz) & 2,4 or 5 \\
\hline Channel with (MHz) & 20 or 40 \\
\hline Modulation & OFDM, DSSS or CCK \\
\hline Number of spatial streams & $1,2,3$ or 4 \\
\hline
\end{tabular}

To achieve greater performance, new features have been added to IEEE 802.11n, among which we can highlight the following ones: changes in OFDM, MIMO, energy saving, antenna technology and wider channel bandwidth.

It should also be noted that in order to improve performance, backward compatibility under special conditions has been reduced. As with 802.11g, when previous devices enter an 802.11n network, the operation of the entire network is greatly reduced.

An IEEE 802.11n access point can work in the following three modes. These modes are the Legacy mode (selecting one the standards among IEEE $802.11 \mathrm{a}$, b, and g), the Mixed mode (working with more than one standard among IEEE $802.11 \mathrm{a}, \mathrm{b}, \mathrm{g}$, and $\mathrm{n}$ ) and the Greenfield mode (IEEE 802.11 n) with maximum performance.

OFDM has been adapted to meet the requirements of IEEE 802.11n. New PHY Layer Convergence Protocol (PLCP) formats, called High Throughput (HT), have been defined for Mixed and Greenfield modes. Moreover, there is a legacy duplicate format as well. This legacy duplicate format is able to duplicate the $20 \mathrm{MHz}$ legacy packet obtaining the $40 \mathrm{MHz}$ channel divided into two $20 \mathrm{MHz}$ halves.

The signal formats vary depending on their mode of operation. The following cases may occur:

Legacy Mode (20 MHz): The signal is comprised by 64 sub-carriers. Sub-carriers -21, -7, 7 and 21, have four pilot signals inserted in them. The signal is then forwarded on sub-carriers from -26 to -1 and from 1 to 26 , where 0 is the center carrier. Sub-carriers from -28 to -1 and from 1 to 28 forward the signal in the HT modes.

Legacy Mode (40 MHz): In this mode, the channel is divided into 128 sub-carriers and the employed channels are two adjacent $20 \mathrm{MHz}$ channels. Sub-carriers from -58 to -2 and from 2 to 58 forward the signal. Furthermore, the six pilot signals are transmitted in sub-carriers $-53,-25,-11,11,25,53$. Signal is transmitted on sub-carriers -58 to -2 and 2 to 58.

Mixed Mode: The legacy standard IEEE 802.11a/g is compatible with the preamble transmitted in the packets. A new MIMO training sequence format is employed in the remaining of the packet. 
Greenfield Mode: This mode is not compatible with legacy standards. Thus, high throughput packets are transmitted without being compatible with IEEE $802.11 \mathrm{a}$, b, and g.

To take full advantage of the available data rate, IEEE 802.11n uses MIMO. It allows up to four different spatial data streams to be transported through the same channel. The antennas available at each end will be those that define one of the limits of these spatial flows.

The capacity of a given system can be identified by simple notation following the format a $\mathrm{x}$ b: c. The letter a stands for the maximum number of transmit antennas, the letter $\mathrm{b}$ stands for the maximum of antennas in the receiver, and the letter c stands for the maximum number of spatial data streams. The $802.11 n$ standard allows up to 4 x 4: 4 of capacity.

Using MIMO increases the power of the hardware circuits and therefore the consumption. In order to achieve a more efficient use of energy, the data is usually transmitted in a "burst", so that there are periods when the system runs at a very slow speed or is inactive, and during that period of inactivity energy is not consumed.

The introduction of beam forming and diversity has improved the technologies associated with antennas. Beam forming improves the performance and the range by focusing the radio signals directly along the path for the receiving antenna. Diversity allows to obtain the optimum signal conditions utilizing the multiple antennas available and combining them or selecting the best subset from a larger number of antennas.

\subsubsection{IEEE 802.11ac}

This standard, known as well as VHT (Very High Throughput), was ratified in 2013 as a new standard. It has been developed to increase the attainable data rates in Wi-Fi networks from a minimum of approximately 1 Gbps to a maximum of 7 Gbps. The manufacturers market the products that meet the standard as 5G WiFi. The standard allows high definition videos, interactive video games and other demanding applications to be transmitted. Its main characteristics are shown in Table 7.

Table 7. Main characteristics of IEEE 802.11ac.

\begin{tabular}{|c|c|}
\hline Characteristics & Values \\
\hline \hline Date standard approval & 2013 \\
\hline Maximum data rate (Gbps) & 6,93 \\
\hline Typical range indoors (Meters) & 70 \\
\hline Typical range outdoors (Meters) & 250 \\
\hline RF Band (GHz) & $5,8 \mathrm{GHz}$ \\
\hline Channel with (MHz) & 20,40, \& 80 MHz \\
& 160 \& 80 + 80 MHz optional \\
\hline Modulation & BPSK, QPSK, 16-QAM, 64-QAM \\
& 256-QAM optional \\
\hline MIMO & Single and multi-user MIMO. Up to 8 spatial streams \\
\hline
\end{tabular}

The IEEE 802.11ac standard utilizes OFDM, which was employed successfully in 
previous 802.11 standards.

Multi-User MIMO (MU MIMO) is implemented in order to achieve the necessitated spectral usage figures. This way, it is possible to obtain the data throughput from the available space. MU-MIMO allows to transmit different data frames to different clients simultaneously. The equipment should be able to employ spatial awareness of remote users, as well as queuing systems for transmission among multiple clients, in order to employ MU-MIMO. The main RF characteristics of the IEEE 802.11ac physical layer are shown in the Table 8.

Table 8. RF characteristics of IEEE 802.11ac.

\begin{tabular}{|c|c|c|}
\hline Characteristics & 802.11ac wave 1 & 802.11ac wave 2 \\
\hline Channel bandwidth & $20 \mathrm{MHz}, 40 \mathrm{MHz}, 80 \mathrm{MHz}$ & $160 \mathrm{MHz}, 80+80 \mathrm{MHz}$ \\
\hline FFT size & $64,128,256$ & 512 \\
\hline Data subcarriers / Pilots & 52 / 4, 108 / 6, 234 / 8 & $468 / 16$ \\
\hline Modulation types & BPSK, QPSK, 16-QAM, 64-QAM & 256-QAM \\
\hline $\begin{array}{c}\text { Spatial streams \& } \\
\text { MIMO }\end{array}$ & 1 & $\begin{array}{l}2 \text { to } 8 \\
\text { TX beamforming, STBC } \\
\text { Multi-user-MIMO }\end{array}$ \\
\hline
\end{tabular}

Up to eight spatial streams can be employed by IEEE 802.11ac. Multiple user MIMO can be utilized as well. It allows to support varied users and presents a multiple access scheme by employing different streams.

The 256-QAM modulation with MIMO, $160 \mathrm{MHz}$ of bandwidth and employing the eight spatial streams is the only one that can achieve the top data rate. When this happens, only two $80 \mathrm{MHz}$ channels or one $160 \mathrm{MHz}$ channel can be accommodated.

\subsubsection{IEEE 802.11ac}

The IEEE 802.11ad WiGig standard has been developed by a collaboration of the Wireless Gigabit Alliance and IEEE. This standard was ratified in 2012 as a new standard. The Wireless Gigabit Alliance was created in order to provide a standard for single multi-gigabit wireless for PCs, handheld devices and consumer electronics. Moreover, it encourages industry convergence employing the $60 \mathrm{GHz}$ spectrum of the unlicensed ISM [21]. Its main characteristics are shown in Table 9.

Table 9. Main characteristics of IEEE 802.11ad.

\begin{tabular}{|c|c|}
\hline Characteristics & Values \\
\hline \hline Operating frequency range (GHz) & 60 \\
\hline Maximum data rate (Gbps) & 7 \\
\hline Typical range indoors (Meters) & $1-10$ \\
\hline Modulation & Various: single carrier and OFDM \\
\hline
\end{tabular}

Session switching between the networks utilizing the $60 \mathrm{GHz}$ WiGig band and the IEEE 802.11 Wi-Fi networks that employ the $2.4 \mathrm{GHz}$ and $5 \mathrm{GHz}$ bands is enabled by a MAC layer standard common to other current IEEE 802.11 standards. In addition, issues such as synchronization, channel access, association and authentication, which is required for $60 \mathrm{GHz}$ 


\section{Macrothink}

operation, have been addressed by an update of the IEEE 802.11ad MAC layer.

Frequencies in the $60 \mathrm{GHz}$ unlicensed spectrum is employed by the WLAN system. Table 10 shows the global allocations of the frequencies.

Table 10. Global frequency allocation.

\begin{tabular}{|c|c|}
\hline Region & Allocation \\
\hline \hline European Union & $57.00-66.00$ \\
\hline USA \& Canada & $57.05-64.00$ \\
\hline South Korea & $57.00-64.00$ \\
\hline Japan & $59.00-66.00$ \\
\hline Australia & $59.4-62.90$ \\
\hline
\end{tabular}

Utilizing four channels with $2.16 \mathrm{GHz}$ with center frequencies of $58.32 \mathrm{GHz}, 60.48 \mathrm{GHz}$, $62.64 \mathrm{GHz}$, and $64.80 \mathrm{GHz}$ is recommended by the ITU-R. As it can be seen, the recommended channel is channel 2 as it is the only globally available channel with its 60.48 GHz center frequency [22]. Table 11 shows the main modulations used at IEEE 802.11ad.

Table 11. IEEE 802.11ad main modulations.

\begin{tabular}{|c|c|}
\hline Modulation & Ideal Raw Bit Rate \\
\hline П/2 DBPSK & 27.5 Mbps \\
\hline П/2 BPSK & \multirow{3}{*}{$\begin{array}{l}385 \mathrm{Mpbs} \\
\text { to } \\
4620 \mathrm{Mbps}\end{array}$} \\
\hline П/2 QPSK & \\
\hline П/2 16-QAM & \\
\hline OFDM-SQPSK & \multirow{4}{*}{$\begin{array}{c}693 \mathrm{Mpbs} \\
\text { to } \\
6756.75 \mathrm{Mbps}\end{array}$} \\
\hline OFDM-QPSK & \\
\hline OFDM-16-QAM & \\
\hline OFDM-64-QAM & \\
\hline П/2 ВPSK & \multirow{2}{*}{$\begin{array}{c}\text { 625.6 Mpbs } \\
\text { to } \\
2503 \mathrm{Mbps}\end{array}$} \\
\hline П/2 QPSK & \\
\hline
\end{tabular}

\subsection{IEEE 802.15 Standard}

The standards comprised under the IEEE working group 802.15 are related to Wireless Personal Area Network (WPAN) technologies. Currently, there are 9 active approved projects. In this section, the applications of the standards and technologies related to the IEEE 802.15 working group for Smart Cities are going to be discussed. Three classes of WPAN were defined [23]. IEEE 802.15.3 is the standard for a high data rate WPAN and it was intended to perform best with multimedia applications which require a high QoS. The IEEE 802.15.1 standard is a medium rate WPAN good for voice communications. Finally, IEEE 802.15.4/LR-WPAN has a low data rate that is suitable for industrial, medical and residential applications that require low cost and low power consumption and do not need a very high QoS.

\subsubsection{IEEE 802.15.1 WPAN/Bluetooth}


The standard IEEE 802.15.1 depicts the operation of WPAN. This standard is based on the technology created by the Bluetooth Special Interest Group. WPANs transmit information over short distances without requiring a big infrastructure, sometimes not being necessary at all, or a connection to the internet. Although it is not possible to communicate between IEEE 802.15.1 devices and IEEE 802.11 devices, some mechanisms were developed in order to allow the coexistence of both technologies [24].

A group of devices that share a physical radio channel are synchronized employing a common clock. One of the devices has the role of the master while the rest are the slaves. This topology is called piconet. In order to avoid interference, it utilizes a frequency hop transceiver. Some of the available frequencies for the hopping pattern are excluded to avoid interferences with static systems.

IEEE 802.15.1 is a protocol for low power consumption short-range wireless communications [25]. It was designed to replace wired computer peripherals with wireless ones. Bluetooth can have two types of topologies, piconet and scatternet. The piconet topology was defined above. A scatternet is comprised of several piconets that overlap in time and space. A device can be part of several piconets simultaneously but it can only be master in one of them. Up to 7 slaves can be part of the same piconet, although there can be devices on standby [26]. The number of slaves that can be put in park mode is 255. In the range of $10 \mathrm{~m}$ up to 20 different piconets can be established. Only one packet at a time can be transmitted between slave and master.

The advantages of IEEE 802.15.1 are its low cost, mobility and that a device can join or leave the network dynamically [27]. The disadvantages include lower reliability, higher power consumption, security threats and lower data rates.

Bluetooth is the proprietary solution of this standard. Version 1.0 and 1.1 were very problematic. Version 1.1 was adopted in 2002 as the IEEE 802.15.1 standard [28]. Bluetooth 1.2 adds the Adaptive Frequency Hopping (AFH) to the previous version and the maximum data transmission rate is $751 \mathrm{~kb} / \mathrm{s}$. It was adopted as the IEEE 802.15.1-2005 standard. Bluetooth 2.0 (2004) enhanced the data rate to 2.1 Mbps. Bluetooth 2.1 (2007) introduced secure simple pairing (SSP). It employs sniff sub rating to reduce power consumption in the low-power mode. Bluetooth 3.0 (2009) improves data transfer speeds to $24 \mathrm{Mbps}$. Bluetooth 4.0 (2010) improves data transmission rates and security. The power consumption is greatly reduced. It does not allow devices to be part of several piconets as a slave device thus, the network topology is the star topology [29]. In Bluetooth 4.1 (2013), a slave is allowed to be connected to several piconets at the same time. Moreover, the device is able to take the role of slave in some intervals and master in others. Thus, the topology options expand. In Bluetooth 4.2 (2014) the internet connectivity, security and throughput are improved. Finally, in Bluetooth 5.0 (2016) range, data rate and advertising channel functionality are improved.

\subsubsection{IEEE 802.15.3 Ultra-wideband (UWB)}

This standard defines an ad-hoc Mac that allows fast network formation, QoE, 128-bit AES encryption and provides the procedures to coexist with other wireless technologies that 
employ the same frequency band. The IEEE 802.15.3-2003 standard operated on the $2.4 \mathrm{GHz}$ band with data rates ranging from $11 \mathrm{Mb} / \mathrm{s}$ to $55 \mathrm{Mb} / \mathrm{s}$ for distances of $70 \mathrm{~m}$ [30].

With the standard IEEE 802.15.3b-2005, the efficiency of the previous standard was increased. The Medium Access Control (MAC), Layer Management Entity (MLME) and Service Access Point (SAP) were better defined. The new policy implied-ACK was implemented to allow polling and to improve the use of channel time. A new channel time allocation method was developed for sharing time to transmit data. Device identifiers could be assigned to group addresses for multicast connections. The recovery network operations were faster than its predecessor. Finally, the possibility of multiple contention periods during a superframe was added.

The IEEE 802.15.3c-2009 standard allowed to operate in the $60 \mathrm{GHz}$ band, data rates higher than $5 \mathrm{~Gb} / \mathrm{s}$, better communication ranges for transmitters as a result of beamforming negotiations and MAC packet aggregation acknowledgment of individual subpackets in order to reduce overhead.

IEEE 802.15.3-2016 allows high rate wireless connectivity for fixed portable and moving devices. PHY and MAC specifications were defined. The transmission of multimedia traffic is now possible with its bandwidth ranging from $110 \mathrm{Mb} / \mathrm{s}$ to $480 \mathrm{Mb} / \mathrm{s}$ presenting itself as a solution to replace wired high-speed serial buses (USB 2.0 and IEEE 1394). Lastly, point-to-point and high rate proximity point-to-point applications are supported. There were difficulties in choosing between MB-OFDM and DS-UWB.

\subsubsection{IEEE 802.15.4/ ZigBee}

This working group was created in 2003 to standardize WPAN [31]. It allows the communication between several devices within an operating space of 10 meters and with minimal power consumption, a small size and low cost. It is intended for devices that need a battery life of several months or years and do not need high data transfer dates.

In 2006 and 2011 the revisions IEEE 802.15.4-2006 and IEEE 802.15.4-2011 were introduced [32]. The latest one defines 12 PHY options where the 2450 direct-sequence spread spectrum (DSSS) is the most employed nowadays. The types of personal area networks (PAN) supported by IEEE 802.15.4 are beacon-enabled PAN and nonbeacon-enabled PAN. Nonbeacon-enabled PANs use Carrier Sense Multiple Access with Collision Avoidance (CSMA-CA) as the channel access mechanism while beacon-enabled PANs employ the slotted CSMA-CA mechanism.

ZigBee is a standard that presents great similarities to IEEE 802.15.4. It describes the communication in the third level of the OSI (Open System Interconnection) model instead of describing the communication of the second level, as IEEE 802.15.4 does. There are two types of devices that can operate in ZigBee. Full-function device (FFD) and reduced-function device (RFD). The FFD can operate as PAN coordinator, coordinator or device. It can communicate with both FFD and RFD. However, RFD can only communicate with FFD and is intended for simple activities such as light switches or passive sensors. A FFD can create its own network becoming the PAN coordinator and selecting a PAN ID in order to avoid 
conflicts with other PANs in the same area.

Star topology, peer-to-peer topology and cluster topology are the three types of topologies that can be implemented with ZigBee.

\subsubsection{IEEE 802.15.6 WBAN}

The IEEE 802.15.6 was created to standardize Wireless Body Area Networks (WBAN) [33]. Three PHY layers are defined, being Narrowband (NB), Ultra Wideband (UWB) and Human Body Communication (HBC), as well as a MAC protocol that facilitates the control of the channel access [34]. There are as well three security levels. Level 0 for unsecured communication, level 1 for authentication only and level 2 for authentication and encryption. For time referenced resource allocations, the hub divides the channel into superframes restricted by beacon periods of equal length.

WBANs usually use three types of nodes: control units (CU), sensor nodes and relaying nodes. Control units require more energy in order to process the information. Sensor nodes need very little power. And, relaying nodes employ enough energy to transfer data [35]. The data rate for UWB is $1 \mathrm{Mb} / \mathrm{s}$. For HBC, it is $2 \mathrm{Mb} / \mathrm{s}$.

This technology can be implemented in countless applications however, most of the research that is being performed nowadays on IEEE 802.15.6 is related to medical and healthcare applications.

\subsubsection{WirelessHART}

WirelessHART is the wireless option of the digital protocol HART [36]. It allows a two-way communication between a host and other devices in order to process data and have access to configurations and diagnostics. It is based on Time Division Multiple Access (TDMA), the physical layer is based on IEEE 802.15.4-2006 [37] and it employs the $2.4 \mathrm{GHz}$ band. The Clear Channel Assessment (CCA) option allows to detect if the channel is occupied before transmitting a message. Channels can also be blacklisted and the transmission power level is configurable, allowing this technology to avoid interferences. All devices are treated equally and have routing capability. It supports mesh and star topologies but the latter is not recommended. A WirelessHART network is comprised of router devices, adapter devices, handheld devices, a gateway device and the network manager.

\subsubsection{ANT+}

ANT+ is a proprietary protocol that operates on the $2.4 \mathrm{GHz}$ frequency band and has low battery consumption [38]. It was developed by the ANT Alliance interest group and its predecessor is the ANT transmission protocol. It allows to collect, transfer and track sensor data for wellness monitoring [39]. Its coin battery cell powers the device for several years and it is able to support complex topologies. ANT+ presents varied profiles. These profiles are preset settings that stablish network rules for specific applications. The format employed for data transmission and channel parameters are some of the aspects included in the settings for each profile. Their available profiles are Heart Rate Monitor, footpod, Bicycle Speed and Weight Scale among others. 


\subsubsection{RuBee}

RuBee is peer-to-peer and transmits data on demand [40]. Unlike Wi-Fi and ZigBee, RuBee operates in the long wavelength band utilizing the magnetic field. It employs the IEEE 1902.1 standard protocol. The devices have a very low power consumption and are classified as controller and responders. They communicate in a peer-to-peer manner employing 131 $\mathrm{kHz}$ radio waves. Its transmission rate is $1024 \mathrm{bits} / \mathrm{sec}$. Both ASK (Amplitude-shift keying) and BPSK modulations are supported by RuBee. Some of the advantages of RuBee are low power consumption, normal operation near steel and water, apt for harsh environments, high security and privacy and controlled volumetric range [41].

\subsubsection{Insteon}

Insteon allows to communicate employing wires and radio waves, resulting in a dual mesh network [42]. It is mostly employed for smart home applications. When a message cannot be transmitted through one platform, it tries the other one. Wireless communications are performed in the $900 \mathrm{MHz}$ frequency. Messages are broadcasted, and all devices act as peers. The theoretical bandwidth for Insteon is 2880 bps. It employs the FSK (Frequency-Shift Keying) modulation and TDMA MAC mechanism. Furthermore, there are two message formats being a standard message that utilizes 10 bytes and an extended message that employs 24 bytes.

\subsubsection{Z-Wave}

Z-Wave is a proprietary protocol designed by Sigma Designs Inc. that provides encryption, integrity and authentication [43]. There is an open source version called open-zwave but it does not support security services. Z-wave support low-power mesh networks with one controller and up to 232 repeater nodes. It performs on the 868/915 MHz frequency bands and employs the BFSK modulation. CSMA/CA is utilized as the network access method. Furthermore, the available data rates are 9.6 kbps and 40 kbps.

\subsection{IEEE 802.16 Standard}

The IEEE 802.16 standard is a progressed set of standards to support broadband fixed and mobile wireless communications. WiMAX is as term devised as an abbreviation for Worldwide Interoperability for Microwave Access, it refers to interoperable implementations of the IEEE 802.16 standards of the Institute of Electrical and Electronics Engineers (IEEE) [44]. Moreover, this standard was published in 2001, its aim was to support communication in the 10-66 GHz frequency band. The later version of IEEE 802.16 was completed in 2009.

Therefore, IEEE 802.16 WMAN technology has been put forward to overcome the drawbacks of WLANs and mobile networks. It has been paid much attention since it was covered larger areas than WLANs while supporting high transmission rates. In addition, it provides various QoS scheduling for supporting heterogeneous traffic including legacy voice traffic, VoIP (Voice over IP), voice and video streams and the Internet data traffic [45]. The prominent features of WiMAX include: quality of service, high-speed Internet, facility over a long distance, scalability, security, and mobility, which proves service better than Wi-Fi 
Internet access. WiMAX is a complement of existing last mile wired technologies such as cable modems and digital subscriber lines Advantage of using WiMax connection. The WiMAX connection speed is used to remote control the smart grid. As a result, it is overcoming the distance limitations of the Wi-Fi networks [46]. WiMAX is capable of delivering data to mobile devices at rates several times faster than current third-generation (3G) cellular speeds. Although, WiMAX offers large municipality coverage supporting class QoS requirements. On the other hand, WiMAX is generally used in licensed spectrum [47].

\subsubsection{IEEE 802.16a}

This amendment addressed certain spectrum issues and enabled the standard to be used at frequencies below the $11 \mathrm{GHz}$ minimum of the original standard of single Carrier (SC) with 256-point transform Orthogonal Frequency Division Multiplexing (OFDM) and 2048 points transform OFDMA (OFD Multiple Access. This was developed for wireless MANs operating on licensed and unlicensed radio-frequency (RF) bands between $2 \mathrm{GHz}$ and $11 \mathrm{GHz}$, Channel size ranges start from 1.75 to $20 \mathrm{MHz}$, at data speeds of up to 75 megabits per second (Mbps), with low latency and efficient use of spectrum space. The maximum range can be extended to approximately 45 kilometers. It uses point-to-multipoint communication and mesh topologies. The standard IEEE 802.16a is ideally usable for advanced communications methods such as voice over IP (VoIP) and prioritized data traffic Mobility can support fixed and pedestrian $[44,48]$.

\subsubsection{IEEE 802.16b}

IEEE 802.16b increased the spectrum that was specified to include frequencies between 5 and $6 \mathrm{GHz}$ of license-exempt (unlicensed) applications. Also, providing for Quality of Service aspects. [49].

\subsubsection{IEEE 802.16c}

The IEEE Standards Board approved IEEE 802.16c in December 2002. The aim was to develop 10- $66 \mathrm{GHz}$ system profiles to aid interoperability specifications for Line-of-Sight broadband wireless access. Its peak data rate in shared carrier reached to 70Mbits/s, with range up to $50 \mathrm{~km}[50,51]$.

\subsubsection{IEEE 802.16d}

This technology was known as IEEE 802.16-2004, it was released in 2004. The standard is provided a number of fixes and improvements to 802.16a, which is including the use of 256 carriers OFDM. Accordingly, this standard was aligned with the ETSI HiperMAN standard to allow for global deployment. The standard only addressed on the fixed operation. It uses point-to-multipoint communication and mesh topologies [52,53].

\subsubsection{IEEE 802.16e}

Also known as an active standard of IEEE 802.16, the standard IEEE 802.16-2005, provided for nomadic and mobile use, is known as the portable or mobile version of WiMAX. The channel bandwidth is from 1,75 to $20 \mathrm{MHz}$. The lower data rates reach up to $15 \mathrm{Mbps}$ 
and up to 90 Mbps. Flexibility is shared among users. It enabled full nomadic and mobile use including handover. The mobility in this technology reached up to $100 \mathrm{Km} / \mathrm{h}$. The supported devices are mobile smart phones, PDAs, notebooks and laptops, among others. Also, it provides better support for QoS and Scalable OFDMA [54,55,56].

\subsubsection{IEEE $802.16 \mathrm{~m}$}

This technology is called progressed air interface. This amendment is being designed to target the successor IMT-2000. It can be operated in a variety of frequency bands in the spectrum. The specific bands supported are 450-470 MHz, 698-960 MHz, 1710-2025 MHz, 2110-2200 MHz, 2300-2400 MHz, 2500-2690 MHz and 3400-3600 MHz. It provides the higher data rates and high mobility, which supports data rates of $100 \mathrm{Mb}$ per seconds for mobile applications and $1 \mathrm{~Gb}$ per seconds for fixed applications. It allows cellular, macro and micro cell coverage; with currently there are no restrictions on the RF bandwidth. Although it is expected to be $20 \mathrm{MHz}$. Coverage range is $3 \mathrm{~km}, 5-30 \mathrm{~km}$ and $30-100 \mathrm{~km}$. This standard is adding support for many new service classes, it increases mobility, and guarantees better Quality of Service (QoS) [57,58].

Moreover, there are other standards of IEEE 802.16; 802.16f, 802.16g, 802.16h, 802.16j and 802.16k. They are deployed for different purposes. Their drafts and pre-drafts are currently under development [59].

\subsection{Mobile technologies}

Mobile technology is the technology utilized for communication mobile devices where the network link is wireless. Therefore, the cellular networks can offer different feature to end-users such as capacity of transmission, less power consumption by mobile devices and large converge area. Therefore, the current devices due to category include smartphones, mobiles, tablets and iPods. According to generation of cellular network [59, 60, 61]. The generation of mobile networks can be detail as follows:

\subsubsection{G}

$2 \mathrm{G}$ is short for second-generation of mobile network technology. It is the first digital cellular standards, including the American IS-95 standard and the GSM standard, which is appeared in the 1990s and mark the second generation (2G) of cellular communication technologies 2G mobile network was launched on Global System for mobile Communications (GSM). In 2G communications, the voice signals are encoded into number of bits as a binary sequence, which enables advanced multiple access solutions. In detail, the mobile standards were relied on different multiple access solutions, making them mutually incompatible [62]. Therefore, GSM was based on a combination of FDMA and time division multiple access (TDMA), where each base station is assigned channels, moreover, these channels are divided up into short time slot. $2 \mathrm{G}$ provided efficient and robust service than $1 \mathrm{G}$ and it was enabled operating short reuse distances. This technology supplied data services for mobile end-users for instance text messages services and small amounts of data over a protocol called MMS. The data rate reach to $10 \mathrm{~Kb}$ per seconds for GSM, and up to $384 \mathrm{~kb}$ per seconds for intermediate standards [61]. 


\subsubsection{G}

3GPP 3rd Generation Partnership Project, Also, 3G mobile network technology is designed to send and receive multimedia services with high and variable bit rates. Radio access of this technology is based on WCDMA (wideband code division multiple access) and utilizes a wide band frequency channel of $5 \mathrm{MHz}$. As a consequence, the 3G wireless radio network planning is significantly differed from the process of narrowband FDMA/TDMA $2 \mathrm{G}$ radio networks and WCDMA (Wideband Code Division Multiple Access). 3G telecommunication networks support services that provide high rates access up to around $2 \mathrm{Mb}$ per seconds. While a number of larger data formats became much more accessible, including standard HTML pages, videos, and music. Moreover, the 3G networks provide 7.2 Mbps or 52 Mbps on 3G HSPA+ [63].

\subsubsection{G}

Fourth generation of cellular wireless standards is abbreviated to 4G. It is superseded to 2G and 3G families of mobile standards. A 4G technology improves the prevailing communication networks by conveying a complete and reliable solution based on IP such as voice, data and multimedia. This system can be serviced to subscribers on every time and everywhere and at quite higher data rates as related to previous generations. Applications that are being made to use a 4G network include: Digital Video Broadcasting (DVB), Multimedia Messaging Service (MMS), High Definition TV and mobile TV. 4G can provide $100 \mathrm{Mb}$ per seconds for high mobility like receiving the service from a moving car or train. $1 \mathrm{~Gb}$ per seconds for low mobility like when walking (pedestrian) [64].

\subsubsection{LTE}

LTE is 3GPP radio interface. It is based on GSM/EDGE and UMTS/HSPA mobile network technologies, and it provides an increase to both capacity and data speed using new techniques for modulation. The carrier bandwidths are $1.4 \mathrm{MHz}$ to $20 \mathrm{MHz}$ and it supports both time-division and frequency division duplexing. Therefore, it provides peak download rates of 300 megabits per second and 75 megabits per second for upload rates, delay before a transfer of data begins following is less than five milliseconds. This technology is IP-based network architecture, which allows for seamless handoff for voice and data to older model cell towers. LTE offers average download and upload speed of 77.8 Mbps and 26.9 Mbps $[64,65]$.

\subsubsection{LTE-A}

The 3GPP Long-Term Evolution-Advanced (LTE-A) offers massive improvements over previous mobile network technologies such as Universal Mobile Telecommunications System (UMTS) and High-Speed Packet Access (HSPA) by introducing a novel physical (PHY) layer and reforming the core network (CN) [60]. LTE Advanced standard is provided heavy enhancement of the Long Term Evolution (LTE) standard. LTE-Advanced can achieve data download rates to three $\mathrm{Gb}$ per seconds and upload rates as high as $1.5 \mathrm{~Gb}$ per seconds. By the comparison, LTE is provided $300 \mathrm{Mb}$ per seconds for downloads and $75 \mathrm{Mb}$ per seconds for uploads. And LTE-Advanced also includes new transmission protocols and 
multiple-antenna schemes that enable smoother hand over between different region of cells, increase data throughput at the level of cell edges, and more bits per second into each hertz of spectrum. Consequently, the result can be higher network capacity, more consistent connections, and cheaper data $[64,66]$.

\subsubsection{LTE-A Pro}

It is a 3GPP release 13. Also known as LTE-Advanced Pro, which is provided 4.5G, 4.5G Pro, 4.9G, Pre-5G networks system. The LTE-A Pro is an evolution of Long Term Evolution (LTE), it is able to function in speeds up to Gbits per seconds. This release incorporated to the numerous new technologies that may be utilized in the $5 \mathrm{G}$ network system standard, it is including: Massive MIMO, 256 Quadrature amplitude modulation, LTE-Unlicensed and LTE Internet of Thing . This technology provides a wide range of enhancements of the challenges in existing services in addition to new and emerging use cases. Moreover, the major advances achieved in Release 13 includes Machine-Type-Communication (MTC) enhancements, carrier aggregation enhancements, Narrowband-IoT Low Power Wide Area (NB-IoT LPWA), public safety features, interworking with $\mathrm{Wi}-\mathrm{Fi}$, single cell-point to multi-point, licensed assisted access, 3D/FD-MIMO, indoor positioning and work on latency reduction $[67,68]$.

\subsubsection{G}

5th generation wireless system is abbreviated to 5G. It continues on the path of LTE, with a massive increase in the demand of the mobile users, 4G networks will be easily changed to $5 G$ with the advanced access technology named Beam Division Multiple Access (BDMA) and Filter Bank multi carrier (FBMC) multiple access. The concept behind BDMA technique considers that it serves multiple mobile users simultaneously. In this mechanism, an orthogonal beam allocates resources to each mobile based station and the BDMA technique divides the antenna beam according to the location of the mobile stations to provide multiple accesses to the base stations. This is leaded to increase the capacity of 5th generation wireless mobile networks. The $5 \mathrm{G}$ standard improves the network system and aims to provide a higher capacity than 4G networks, which allows massive connections of mobile users to base stations. It also carries out machine-to-machine, reliable, and density machine communications. The characteristics of 5G provides high data rates, which allows tens of megabits per second for tens of thousands of users, data rates of hundred megabits per second for metropolitan areas networks, one Gb per second can be provided simultaneously to numerous mobile users on the same connection point and, it can supply several hundreds of thousands of simultaneous connections for wireless network sensors [60, 68]. According to Fig.2, the spectrum of mobile network services between both LTE and $5 \mathrm{G}$ technologies is depicted for serving the applications. 


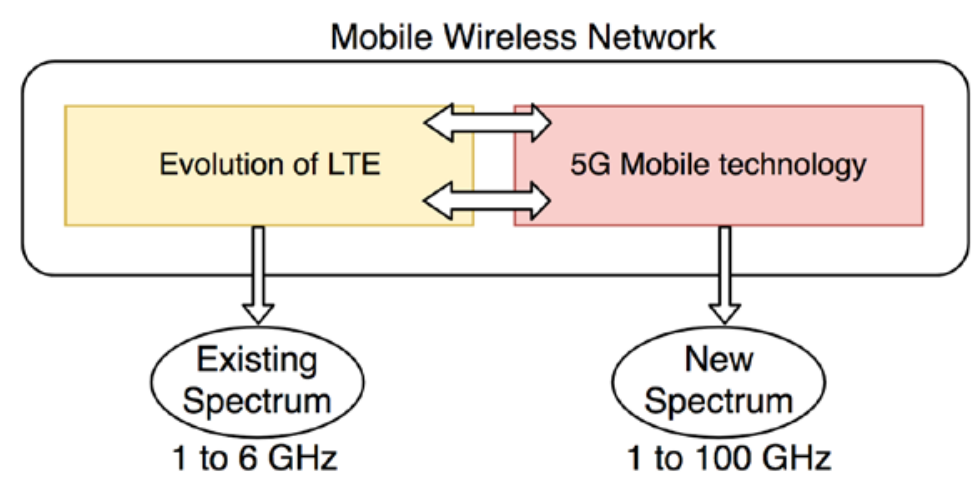

Figure 2. Comparison between spectrum of 5G and LTE.

\subsubsection{LoRa}

LoRa stands for Long Range and it is a proprietary technology. This spread modulation scheme was developed in 1940 and employs the unlicensed band below $1 \mathrm{GHz}$. Its advantages are its low cost, its robustness from interferences and its long-range transmissions. It is being employed in IoT solutions [69, 70]. The physical layer of LoRa modulates the signal in SUB-GHz ISM band. It is using a proprietary spread spectrum technique, which is developed by Semtech Corporation. According to the network architecture of LoRa shown in Fig. 3, LoRa provides a variety of advantages. LoRa utilizes from the $868 \mathrm{MHz}$ to the 915 $\mathrm{MHz}$ ISM band. This band has a very wide coverage range, about $5 \mathrm{Km}$ in urban areas and, $15 \mathrm{Km}$ in suburban areas. Therefore, LoRa is easy to deploy due to its network architecture and its gateway is designed to service thousands of end devices. The data rate transmission can be from $0.3 \mathrm{kbps}$ to $27 \mathrm{Kbps}$ for $125 \mathrm{KHz}$ of bandwidth. It is widely used for M2M of IoT applications. Thus, LoRa modulation has constant envelope modulation which is similar to the FSK modulation type. LoRa technology provides low power with high efficiency at a low cost.

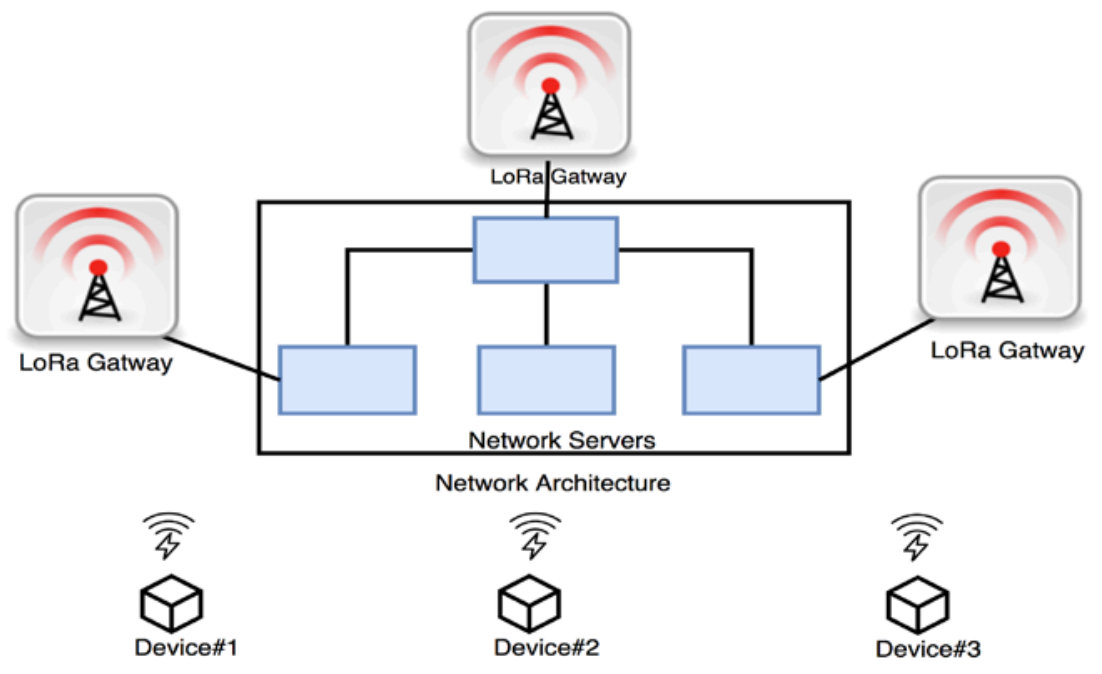

Figure 3. Network architecture of LoRa. 


\subsubsection{SIGFOX}

This technology uses Ultra-Narrow Band (UNB) spectrum channel (usually less than 2.5kHz) with Differential Binary Phase Shift Keying (BPSK) modulation for the transmission. In SIGFOX, the device starts transmitting the data by sending three uplink packages in the sequence on three carrier frequencies from the device to the base station. The base station receives the packages (may be three of them or one of them, whether two of the packets are lost during the transmission due to interference from other system signals or high collision of the network traffic). SIGFOX initially supported only uplink communication later. However, it evolved into a bidirectional connection. Therefore, this technology employs 100 bps as maximum throughput. SIGFOX coverage is 30 to $50 \mathrm{~km}$ in rural environments and 3 to 10 Km urban environments. SIGFOX provides the following advantages:

- Supports wide coverage area and it is utilized for low data rate applications.

- It is a lightweight protocol, which efficiently manipulates smaller messages.

- It uses about 26 bytes for transport layer and 12 bytes of data layer. Therefore, it uses less protocol coverage compared to conventional wireless systems. In conventional wireless systems, the IP stack uses about 40 bytes for the transport layer and 12 bytes for the data layer.

- $\quad$ Due to less data to be transmitted, less energy is needed. Therefore, the conservation of battery life will be enhanced. This increases the network capacity to a greater extent.

- Implementation of this technology is used in many applications such as smart city, metering, automotive systems, and cellular connectivity to offload traffic, etc.

\section{Discussion}

In this section, the main characteristics of the different wireless technologies are presented. The problems of unlicensed bands occupation and coexistence between technologies are discussed. Moreover, wireless technologies are compared on power consumption.

Different domains of a Smart City may require different wireless solutions considering the type of applications and their needs. Table 12 presents some of the actual proposals and implementations of applications for varied domains of smart cities and the wireless technology they employ. As it can be seen, most types of solutions are utilized. However, there is a prevalence in the use of WiFi for data transmission.

\subsection{IEEE 802.11}

WiFi standards are the most employed for domestic and entrepreneurial environments to provide internet access to countless devices. It is also being employed to provide free internet access to citizens by deploying access points all over the city. All types of data can be transmitted with WiFi, although earlier versions of the standard may have difficulties to transmit high quality multimedia traffic. The comparison of bitrates of the wireless technologies is shown in Fig. 4. As it can be seen, the bitrate for IEEE 802.11 has been 
increasing as new standards were released. Users can move freely without having problems when connecting to other access points of the network. As a disadvantage, WiFi connections are less stable than wired ones, the service radius is limited, and it presents high signal attenuation [79]. Table 13 presents the characteristics of WiFi standards. WiFi radius has a medium range. Devices can pull away until distances ranging from $20 \mathrm{~m}$ to $70 \mathrm{~m}$ for indoors and $100 \mathrm{~m}$ to $250 \mathrm{~m}$ for outdoors. Between the standards IEEE 802.11a/b/n/g, IEEE 802.11b has a stronger signal for long distances. IEEE 802.11b and IEEE 802.11n are the better ones for close ranges $[80,81]$. It can be specially indicated for the governance, infrastructure, economy and people dimensions of a Smart City. The employed frequency bands are unlicensed, so precautions should be taken when designing the network. Interferences may detriment the Quality of Service (QoS) of the system being deployed.

Table 12. Wireless technologies employed in different domains of a Smart City.

\begin{tabular}{|l|l|l|}
\hline \multicolumn{1}{|c|}{ Reference } & \multicolumn{1}{c|}{ Domain } & \multicolumn{1}{c|}{ Technology } \\
\hline \hline Andrea Zanella et al. [71] & Health & WiFi and 802.15.4 \\
\hline Andrea Zanella et al. [71] & Waste management & 3G and 4G \\
\hline Andrea Zanella et al. [71] & Air quality monitoring & Bluetooth, WiFi and 802.15.4 \\
\hline Andrea Zanella et al. [71] & Noise monitoring & IEEE 802.15.4 \\
\hline Andrea Zanella et al. [71] & Traffic congestion & IEEE 802.15.4, Bluetooth and WiFi \\
\hline Andrea Zanella et al. [71] & Smart parking & IEEE 802.15.4 \\
\hline Andrea Zanella et al. [71] & Smart lighting & IEEE 802.15.4 and WiFi \\
\hline Andrea Zanella et al. [71] & Automation and salubrity of public buildings & IEEE 802.15.4 and WiFi \\
\hline Evgeny Khorov et al. [72] & Environmental monitoring & IEEE 802.11ah \\
\hline Evgeny Khorov et al. [72] & Healthcare & IEEE 802.11ah \\
\hline Evgeny Khorov et al. [72] & Smart meters (gas, power consumption) & IEEE 802.11ah \\
\hline Marco Centenaro et al [73] & Environmental monitoring & LPWAN and LoRa \\
\hline Miguel Castro et al. [74] & Smart lighting & 6LowPAN and CoAP \\
\hline Zhanlin Ji et al. [75] & Smart parking & RFID, \\
& & WiFi/WiMax and VANET \\
\hline Muhammad Saqib Jamil et al. [76] & Air pollution monitoring & LTE-M and ZigBee \\
\hline Yiheng Chen et al. [77] & Water quality monitoring & WiFi \\
\hline Kevin Abas et al. [78] & Video surveillance & WiFi \\
\hline
\end{tabular}




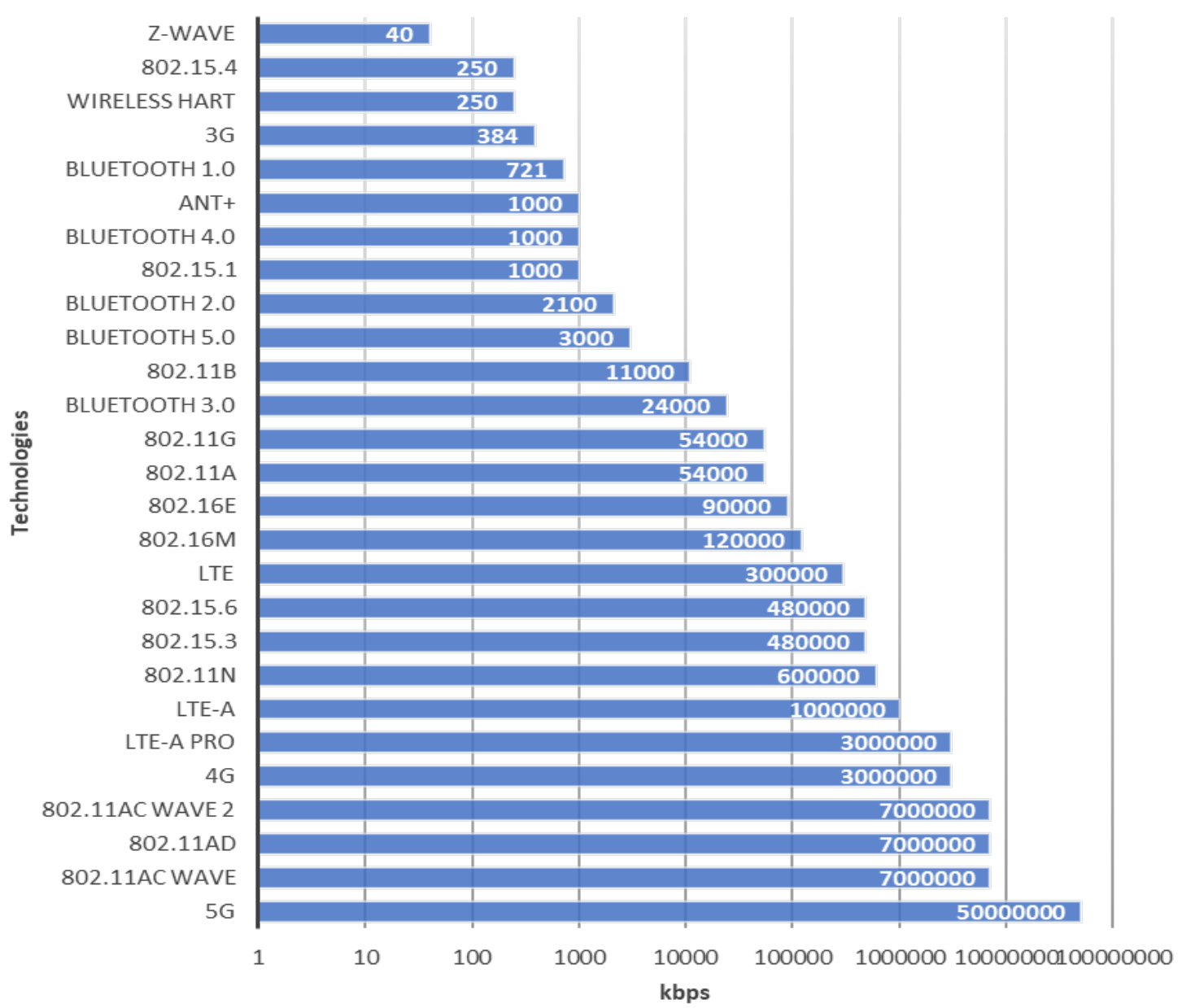

Figure 4. Comparison of the bitrates of wireless technologies.

Table 13. WiFi standards characteristics.

\begin{tabular}{|c|c|c|c|c|c|c|c|}
\hline Technologies & $\begin{array}{l}\text { Indoor/ } \\
\text { Outdoor }\end{array}$ & Bitrate & $\begin{array}{l}\text { Freq. } \\
\text { bands }\end{array}$ & License & Bandwidth & Modulation & MIMO \\
\hline IEEE 802.11 & $20 \mathrm{~m} / 100 \mathrm{~m}$ & 2 Mbps & $2.4 \mathrm{GHz}$ & Unlicensed & $20 \mathrm{MHz}$ & FHSS and DSSS & - \\
\hline IEEE 802.11b & $35 \mathrm{~m} / 140 \mathrm{~m}$ & 11 Mbps & $2.4 \mathrm{GHz}$ & Unlicensed & $20 \mathrm{MHz}$ & HR-DSSS & - \\
\hline IEEE 802.11a & $35 \mathrm{~m} / 119 \mathrm{~m}$ & 54 Mbps & $5 \mathrm{GHz}$ & Unlicensed & $20 \mathrm{MHz}$ & OFDM & - \\
\hline IEEE 802.11g & $45 \mathrm{~m} / 90 \mathrm{~m}$ & 54 Mbps & $2.4 \mathrm{GHz}$ & Unlicensed & $22 \mathrm{MHz}$ & $\begin{array}{l}\text { OFDM/ DSSS/ } \\
\text { CCK }\end{array}$ & - \\
\hline IEEE 802.11n & $70 \mathrm{~m} / 250 \mathrm{~m}$ & 600 Mbps & $\begin{array}{l}2.4 \mathrm{GHz} / 5 \\
\mathrm{GHz}\end{array}$ & Unlicensed & $\begin{array}{lll}20 & \mathrm{MHz} / & 40 \\
\mathrm{MHz} & \end{array}$ & OFDM & $4 \times 4$ \\
\hline $\begin{array}{l}\text { IEEE 802.11ac } \\
\text { wave }\end{array}$ & $70 \mathrm{~m} / 250 \mathrm{~m}$ & 7000 Mbps & $5 \mathrm{GHz}$ & Unlicensed & $80 \mathrm{MHz}$ & 64-QAM & MU-MIMO \\
\hline IEEE 802.11ad & $10 \mathrm{~m} / \mathrm{n} / \mathrm{a}$ & 7000 Mbps & $60 \mathrm{GHz}$ & Unlicensed & $2.16 \mathrm{GHz}$ & $\begin{array}{l}\text { Single Carrier/ } \\
\text { OFDM }\end{array}$ & $10 \times 10$ \\
\hline $\begin{array}{l}\text { IEEE } 802.11 \text { ac } \\
\text { wave } 2\end{array}$ & $70 \mathrm{~m} / 250 \mathrm{~m}$ & $7000 \mathrm{Mbps}$ & $5 \mathrm{GHz}$ & Unlicensed & $\begin{array}{l}80 \mathrm{MHz} / 160 \\
\mathrm{MHz}\end{array}$ & 256-QAM & $\begin{array}{l}\text { MU_MIMO } \\
8 \text { X } 8\end{array}$ \\
\hline
\end{tabular}




\subsection{IEEE 802.15}

IEEE 802.15 standards and their private counterparts are mostly employed in WSN and systems that require low power consumption and small data transmissions. Multimedia traffic is not usually forwarded through these technologies. Voice traffic is often transmitted employing Bluetooth because it is the communication technology employed by a great number of wireless peripherals such as headphones and hands-free kits. ZigBee and similar technologies are not commonly utilized for voice traffic. Bluetooth cost is low and it is fairly easy to install. However, it is not intended for long-range communications and has some security flaws. ZigBee is a low-cost power saving solution that includes collision avoidance. As a disadvantage, it is slower than other solutions [79]. Table 14 presents the characteristics of IEEE 802.15 standards, Bluetooth and other proprietary technologies. The distance range is shorter than that of WiFi. The transmission rate is usually smaller because it was intended for short transmissions. The $2.4 \mathrm{GHz}$ ISM band is commonly used which result in interference and coexistence problems. ZigBee and similar proprietary solutions allow a great number of nodes as it is usually employed for monitoring applications. These technologies are better intended for the management, infrastructures and technology dimensions of a Smart City.

\subsection{IEEE 802.16}

The IEEE 802.16 standard was created to provide a communication channel to devices situated on further areas. For that reason, the maximum distance obtainable by IEEE 802.16 ranges from $30 \mathrm{~km}$ to $100 \mathrm{~km}$, as it can be seen in Table 15. As an inconvenience, installing WiMax can be quite expensive. All kinds of data traffic can be transmitted with IEEE 802.16 [79]. However, WiMax can have some difficulties with high definition multimedia traffic. They operate on both licensed and unlicensed spectrums, so it is possible to avoid high interferences. This technology can be adequate for the technology and management dimensions of a Smart City.

\subsection{Mobile technologies}

As mobile phones evolved, better and faster connections were required. Compared to other wireless solution, mobile technologies usually use licensed bands which helps to avoid interferences caused by other technologies. Like IEEE 802.16 standards, this technology allows to have long-distance connections. As shown on Table 16, the most recent solution, 5G, permits to stablish a connection up to $500 \mathrm{~km}$ of distance. Recent mobile technologies have high data rates and spectrum efficiency. Multimedia content can be transmitted, and voice data is transmitted with high quality. As a drawback, it is a costly solution and newer versions are firstly deployed on big cities [79]. This technology is intended for the governance, economy, infrastructure, technology and people dimensions of a smart city. 
Table 14. Characteristics of 802.15 standards and similar proprietary technologies.

\begin{tabular}{|c|c|c|c|c|c|c|c|}
\hline Technologies & Distance & Bitrate & $\begin{array}{l}\text { Freq. } \\
\text { bands }\end{array}$ & License & Int/Ext & $\begin{array}{l}\text { Energy } \\
\text { consumption }\end{array}$ & Capability \\
\hline IEEE 802.15.1 & $10 \mathrm{~m}$ & $1 \mathrm{Mbps}$ & 2.4GHz & unlicensed & $\begin{array}{l}\text { Indoor/ } \\
\text { Outdoor }\end{array}$ & 0-10 dBm & $\begin{array}{l}8 \text { actives } \\
255 \text { park } \\
\text { mode }\end{array}$ \\
\hline Bluetooth 1.0 & $2 m$ & 721 kbps & $2.4 \mathrm{GHz}$ & unlicensed & $\begin{array}{l}\text { Indoor/ } \\
\text { Outdoor }\end{array}$ & Not specified & - \\
\hline Bluetooth 1.2 & - & 721 Kbps & $2.4 \mathrm{GHz}$ & unlicensed & $\begin{array}{l}\text { Indoor/ } \\
\text { Outdoor }\end{array}$ & Not specified & $\begin{array}{l}8 \text { actives } \\
255 \text { park } \\
\text { mode }\end{array}$ \\
\hline Bluetooth 2.0 & $10 \mathrm{~m}$ & 2.1 Mbps & $2.4 \mathrm{GHz}$ & unlicensed & $\begin{array}{l}\text { Indoor/ } \\
\text { Outdoor }\end{array}$ & Not specified & $\begin{array}{l}8 \text { actives } \\
255 \text { park } \\
\text { mode }\end{array}$ \\
\hline Bluetooth 3.0 & $10 \mathrm{~m}$ & 24 Mbps & $2.4 \mathrm{GHz}$ & unlicensed & $\begin{array}{l}\text { Indoor/ } \\
\text { Outdoor }\end{array}$ & Not specified & $\begin{array}{l}8 \text { actives } \\
255 \text { park } \\
\text { mode }\end{array}$ \\
\hline Bluetooth 4.0 & $100 \mathrm{~m}$ & $1 \mathrm{Mbps}$ & $2.4 \mathrm{GHz}$ & Unlicensed & $\begin{array}{l}\text { Indoor/ } \\
\text { Outdoor }\end{array}$ & Not specified & \begin{tabular}{|l}
8 actives \\
255 park \\
mode
\end{tabular} \\
\hline \begin{tabular}{|l|} 
Bluetooth 5.0 \\
{$[82]$}
\end{tabular} & $350 \mathrm{~m}$ & $\begin{array}{l}1-2-3 \\
\text { Mbps }\end{array}$ & $2.4 \mathrm{GHz}$ & Unlicensed & $\begin{array}{l}\text { Indoor/ } \\
\text { Outdoor }\end{array}$ & $1-100 \mathrm{~mW}$ & $\begin{array}{l}8 \text { actives } \\
255 \text { park } \\
\text { mode }\end{array}$ \\
\hline IEEE 802.15.3 & $10-100 \mathrm{~m}$ & $\begin{array}{l}\text { 110-480 } \\
\text { Mbps }\end{array}$ & $\begin{array}{l}3.1-10.6 \\
\text { GHz } \\
\end{array}$ & Licensed & Indoor & $-41.3 \mathrm{dBM} / \mathrm{MHz}$ & - \\
\hline IEEE 802.15.4 & $10-75 \mathrm{~m}$ & $\begin{array}{l}20 \text { kbps/ } \\
40 \text { kbps/ } \\
250 \text { Kbps } \\
\end{array}$ & $\begin{array}{l}\text { 868/915 } \\
\text { MHz; } 2.4 \\
\text { GHz }\end{array}$ & $\begin{array}{l}\text { Licensed/ } \\
\text { Unlicensed }\end{array}$ & $\begin{array}{l}\text { Indoor/ } \\
\text { Outdoor }\end{array}$ & $\begin{array}{l}-25 \mathrm{dBm} /-0 \\
\mathrm{dBm}\end{array}$ & 254 \\
\hline $\begin{array}{l}\text { IEEE 802.15.6 } \\
\text { [83] }\end{array}$ & $\begin{array}{l}10 \mathrm{~m} \\
30 \mathrm{~m}\end{array}$ & $\begin{array}{l}480 \text { Mbps } \\
50 \mathrm{Mbps}\end{array}$ & $\begin{array}{l}\text { 3.1-10.6 } \\
\text { GHz }\end{array}$ & Unlicensed & Indoor & - & - \\
\hline ANT $+[83]$ & $100 \mathrm{~m} / 20 \mathrm{~m}$ & $1 \mathrm{Mbps}$ & $2.4 \mathrm{GHz}$ & Unlicensed & $\begin{array}{l}\text { Indoor/ } \\
\text { Outdoor }\end{array}$ & - & 200 \\
\hline \begin{tabular}{|l} 
RuBee (IEEE \\
1902.1) [83]
\end{tabular} & $30 \mathrm{~m}$ & 1024 bps & $132 \mathrm{KHz}$ & Licensed & \begin{tabular}{|l} 
Indoor/ \\
Outdoor
\end{tabular} & - & - \\
\hline Insteon [83] & - & 2880 bps & $900 \mathrm{MHz}$ & Unlicensed & $\begin{array}{l}\text { Indoor/ } \\
\text { Outdoor }\end{array}$ & - & - \\
\hline Z-Wave [83] & $30 \mathrm{~m}$ & $\begin{array}{l}9.6 \mathrm{kbps} \\
/ 40 \mathrm{kBps}\end{array}$ & $\begin{array}{l}\text { 868/915 } \\
\mathrm{MHz} \\
2.4 \mathrm{GHz} \\
\end{array}$ & $\begin{array}{l}\text { Licensed/ } \\
\text { Unlicensed }\end{array}$ & $\begin{array}{l}\text { Indoor/ } \\
\text { Outdoor }\end{array}$ & Low & 232 \\
\hline $\begin{array}{l}\text { WirelessHART } \\
{[84]}\end{array}$ & $\begin{array}{l}75 \mathrm{~m} / 100 \mathrm{~m} \\
\text { outdoor/ } 200 \\
\text { m line-of-sight }\end{array}$ & $250 \mathrm{Kbps}$ & $2.4 \mathrm{GHz}$ & Unlicensed & $\begin{array}{l}\text { Indoor/ } \\
\text { Outdoor }\end{array}$ & $10 \mathrm{dBm}$ & 160 \\
\hline
\end{tabular}


Table 15. Characteristics of IEEE 802.16 standards.

\begin{tabular}{|c|c|c|c|c|c|c|c|c|c|}
\hline Technology & Standard & Distance & Data rate & Freq. Band & License & $\begin{array}{l}\text { Indoor/ } \\
\text { outdoor }\end{array}$ & Mobility & Topology & Latency \\
\hline $\begin{array}{l}\text { IEEE } \\
\text { 802.16e } \\
\text { (WiMax) }\end{array}$ & 3GPP & $50 \mathrm{~km}$ & $\begin{array}{l}15 \text { Mbps } \\
90 \text { Mbps }\end{array}$ & $\begin{array}{lr}2.4 \mathrm{GHz} \text { and } \\
2.4835 \mathrm{GHz} \\
\text { or between } \\
5.75 \quad \mathrm{GHz} \\
\text { and } & 5.850 \\
\text { GHz } & \end{array}$ & Licensed & $\begin{array}{l}\text { Indoor/ } \\
\text { Outdoor }\end{array}$ & - & $\begin{array}{l}\text { Point-to-multipoint } \\
\text {, mesh }\end{array}$ & $30 \mathrm{~ms}$ \\
\hline $\begin{array}{l}\text { IEEE } \\
\text { 802.16m } \\
\text { (Mobile } \\
\text { WiMax) }\end{array}$ & 3GPP & $\begin{array}{l}30-100 \\
\mathrm{~km}\end{array}$ & $\begin{array}{l}120 \mathrm{Mbit} / \\
\mathrm{s} \\
\text { downlink/ } \\
60 \mathrm{Mbit} / \mathrm{s}\end{array}$ & $\begin{array}{ll}\text { up } & \text { to } \\
100 \mathrm{MHz} & \end{array}$ & Both & $\begin{array}{l}\text { Indoor } \\
\text { /Outdoor }\end{array}$ & $120 \mathrm{~km} / \mathrm{h}$ & $\begin{array}{l}\text { Point-to-multipoint } \\
\text {, mesh }\end{array}$ & 27.5 \\
\hline
\end{tabular}

\subsection{Unlicensed bands occupation and coexistence}

Some of the most employed wireless technologies operate on unlicensed bands. The most common is $2,4 \mathrm{GHz}$ ISM band but $5 \mathrm{GHz}$ band is started to be more employed, as it can be seen in Fig. 5. Some of the problems that arise from channel occupancy are addressed in [85]. They determine that the main problems of a crowded spectrum are achieving high performance, supporting overlapping WSN and managing interferences. Considering a domestic environment, many devices employing IEEE 802.11, IEEE 802.15.1 and IEEE 802.15.4, such as wireless mouse or wireless headphones, are utilized in the same house or building. Those technologies employ the 2,4 GHz ISM band resulted in a congested and overloaded frequency spectrum. Also, other home appliances such as microwave ovens operate as well on the $2,4 \mathrm{GHz}$ band generating great noise. Authors propose establishing more unlicensed frequency bands or using spread spectrum techniques. The presence of IEEE 802.11 technologies can increase IEEE 802.15.4 packet loss however, failures are negligible employing -10 dBm transmit power [86]. Higher power transmissions could be a solution, but it could not be indicated for some applications like BANs due to electromagnetic energy absorption by the human body. It also would increase interference with other users of the 2,4 $\mathrm{GHz}$ ISM band and be susceptible of attacks like eavesdropping. Some suggestions presented in [87] include keeping low the power levels in order to allows coexistence and frequency reuse and employing Cognitive Radio Systems (CRS) to utilize the gaps with low spectrum occupancy. Employing this technique is advised for short range communications for it not to interfere with other users of the spectrum. 
Table 16. Characteristics of mobile technologies.

\begin{tabular}{|c|c|c|c|c|c|c|c|c|c|}
\hline Technology & Standard & Distance & Data rate & $\begin{array}{l}\text { Freq. } \\
\text { Band }\end{array}$ & Licensed & $\begin{array}{l}\text { Indoor/ } \\
\text { outdoor }\end{array}$ & Mobility & Topology & Latency \\
\hline $3 G$ & IMT-2000 & $35 \mathrm{~km}$ & $384 \mathrm{~kb} / \mathrm{s}$ & $\begin{array}{l}1.25 \\
\mathrm{MHz} / \\
5 \mathrm{MH}\end{array}$ & Both & \begin{tabular}{|l} 
Indoor \\
/Outdoor
\end{tabular} & $90 \mathrm{~km} / \mathrm{h}$ & - & $25 \mathrm{~ms}$ \\
\hline $4 G$ & $\begin{array}{l}\text { Single } \\
\text { unified } \\
\text { LTE } \\
\text { WiMax }\end{array}$ & $100 \mathrm{~km}$ & $\begin{array}{l}3 \mathrm{~Gb} / \mathrm{s}, \\
1,5 \mathrm{~Gb} / \mathrm{s}\end{array}$ & $\begin{array}{l}1.8-2.6 \\
\mathrm{GHz}\end{array}$ & Both & \begin{tabular}{|l} 
Indoor \\
/Outdoor
\end{tabular} & $110 \mathrm{~km} / \mathrm{h}$ & - & $15 \mathrm{~ms}$ \\
\hline LTE & $\begin{array}{l}\text { 3GPP } \\
\text { Rel.8 }\end{array}$ & $75 \mathrm{~km}$ & $\begin{array}{l}30 \\
0 \mathrm{Mb} / \mathrm{s}(\mathrm{DL}), \\
75 \\
\mathrm{Mb} / \mathrm{s}(\mathrm{UL})\end{array}$ & $\begin{array}{l}2.5 \mathrm{GHz} \\
5 \mathrm{GHz}, 10 \\
\mathrm{GHz}\end{array}$ & Both & \begin{tabular}{|l} 
Indoor \\
/Outdoor
\end{tabular} & $350 \mathrm{~km} / \mathrm{h}$ & Star & $15 \mathrm{~ms}$ \\
\hline LTE-A & $\begin{array}{l}\text { 3GPP } \\
\text { Release } \\
10,11,12\end{array}$ & $200 \mathrm{~km}$ & $\begin{array}{l}1 \mathrm{~Gb}(\mathrm{DL}), \\
500 \mathrm{Mb} / \mathrm{s}(\mathrm{U} \\
\mathrm{L})\end{array}$ & $\begin{array}{ll}2.5 & \mathrm{GHz} \\
5 \mathrm{GHz}, & 10 \\
\mathrm{GHz}, & 15 \\
\mathrm{GHz}, & 20 \\
\mathrm{GHz} & \end{array}$ & Both & \begin{tabular}{|l} 
Indoor \\
/Outdoor
\end{tabular} & $\begin{array}{l}350 \mathrm{~km} / \mathrm{h}- \\
500 \mathrm{~km} / \mathrm{h}\end{array}$ & $\begin{array}{ll}\text { Point } & \text { to } \\
\text { point }\end{array}$ & $10 \mathrm{~ms}$ \\
\hline LTE-A Pro & $\begin{array}{l}\text { 3GPP } \\
\text { Release } 13 \\
\text { and } \\
\text { beyond }\end{array}$ & $150 \mathrm{~km}$ & $\begin{array}{l}\text { higher data } \\
\text { rate beyond } \\
3 \text { Gbps }\end{array}$ & \begin{tabular}{|l} 
licensed \\
(400 $\mathrm{MHz}$ \\
to \\
GHz) \\
unlicense \\
d $(5 \mathrm{GHz})$ \\
spectrum
\end{tabular} & Both & \begin{tabular}{|l|} 
Indoor \\
/Outdoor
\end{tabular} & $500 \mathrm{~km} / \mathrm{h}$ & $\begin{array}{l}\text { End-to-End } \\
\text { Network } \\
\text { Slicing for } \\
\text { Multiple }\end{array}$ & $2 \mathrm{~ms}$ \\
\hline $5 G$ & $\begin{array}{l}\text { Single } \\
\text { unified, } \\
4 \mathrm{G} \\
\text { WWWW }\end{array}$ & $300 \mathrm{~km}$ & $10-50 \mathrm{~Gb} / \mathrm{s}$ & $\begin{array}{l}1.8-2.6 \\
\text { GHz- } \\
30-300 \\
\text { GHz, UP } \\
60 \mathrm{GHz}\end{array}$ & Both & \begin{tabular}{|l|} 
Indoor \\
/Outdoor
\end{tabular} & $500 \mathrm{~km} / \mathrm{h}$ & $\begin{array}{l}\text { End-to-End } \\
\text { Network } \\
\text { Slicing for } \\
\text { Multiple }\end{array}$ & $1 \mathrm{~ms}$ \\
\hline LoRa & Propietary & $22 \mathrm{Km}$ & $\begin{array}{l}290 \text { bps-50 } \\
\text { kbps }\end{array}$ & \begin{tabular}{|rr}
668 & $\mathrm{MHz}$ \\
and & 900 \\
$\mathrm{MHz}$ &
\end{tabular} & $\begin{array}{l}\text { Unlicens } \\
\text { ed }\end{array}$ & $\begin{array}{l}\text { Indoor/O } \\
\text { utdoor }\end{array}$ & - & Star & - \\
\hline
\end{tabular}

Bluetooth, ZigBee and WiFi share the $2.4 \mathrm{GHz}$ band. Bluetooth and UWB employ adaptive frequency hopping to avoid interferences (channel collision) and ZigBee and WiFi use dynamic frequency selection and transmission power control. There are three types of solutions to avoid interference between Bluetooth and WLAN [88]. The first one is collaborative solutions where Bluetooth and WLAN have to exchange messages. They are called Packet Traffic Arbitration (PTA), where time slots are assigned to avoid collisions, and Alternating Wireless Medium Access (AWMA) where TDMA is employed. The non-collaborative solutions do not perform a message exchange between Bluetooth and WLAN. Adaptive Frequency Hopping (AFH) changes the hopping sequence to avoid 
channels with high interference. Listen-Before-Talk (LBT) employs CSMA/CA so the channel is checked before transmitting. However, the radiation power of Bluetooth is lower than the access point, so the WLAN may not detect the Bluetooth device and begin the transmission, resulting in collision. The OverLap Avoidace (OLA) Mechanism consider the Bluetooth device and the Access Point separately. The slot size of the Data-link is adjusted in order to avoid collision. Several experiments have been performed in order to determine the effects of interferences between Bluetooth and Wi-Fi. In [89], data traffic, a Bluetooth voice application and the performance of the WLAN is considered. They conclude that packet loss is higher when the Access Pint and the Bluetooth device are closer. They also study interference mitigation techniques such as the backoff strategy (BIAS) and adapting the frequency hopping pattern for Bluetooth devices. Their results show that there is not any technique that can improve the performance for all applications and suggest employing a combination of both. In [90], an analysis of the packet error rate under interferences from WLAN and Bluetooth is performed. They state that when the distance between the source and destination of a WLAN transmission is less than $3 \mathrm{~m}$, there is no interference from a ZigBee network. The higher the number of WLAN Access points, the higher the packet error rate of ZigBee. Their studies show that the major interference for ZigBee comes from WLAN. Bluetooth interferences decrease abruptly when the distance between devices increases.

The coexistence between IEEE 802.15.4, IEEE 802.11 and Bluetooth Low Energy considering distance, packet interval and channel separation is analyzed in [91]. The comparison of the distance of short and medium ranged technologies is shown in Fig. 6 and the one for long-ranged technologies is available in Fig. 7. Bluetooth Low Energy is more affected by IEEE 802.15.4 interferences for distances around $7 \mathrm{~m}$. IEEE 802.15.4 is more affected by IEEE 802.11 with distances up to $12 \mathrm{~m}$. When the packet interval is varied, BLE networks are more affected by IEEE 802.15.4, being around 5 times less affected by IEEE 802.11. When considering interferer channel separation BLE is again more affected by IEEE 802.15.4 than by IEEE 802.11. An experiment is performed in [92] to determine the effects of interferences between IEEE 802.11 and IEEE 802.15.4. Results show that WLAN technologies can interfere greatly with ZigBee and interferences created by ZigBee devices are barely noticeable to WLAN technologies. They suggest a $7 \mathrm{MHz}$ offset between operational frequencies in order to avoid interferences. Authors in [93] propose an adaptive radio channel allocation scheme that improves the coexistence between IEEE 802.11 and IEEE 802.15.4. Reaching between $97 \%$ and $86 \%$ of success rate. Employing multiple channels is considered in [94] in order to overcome interference and obtain a higher performance. 


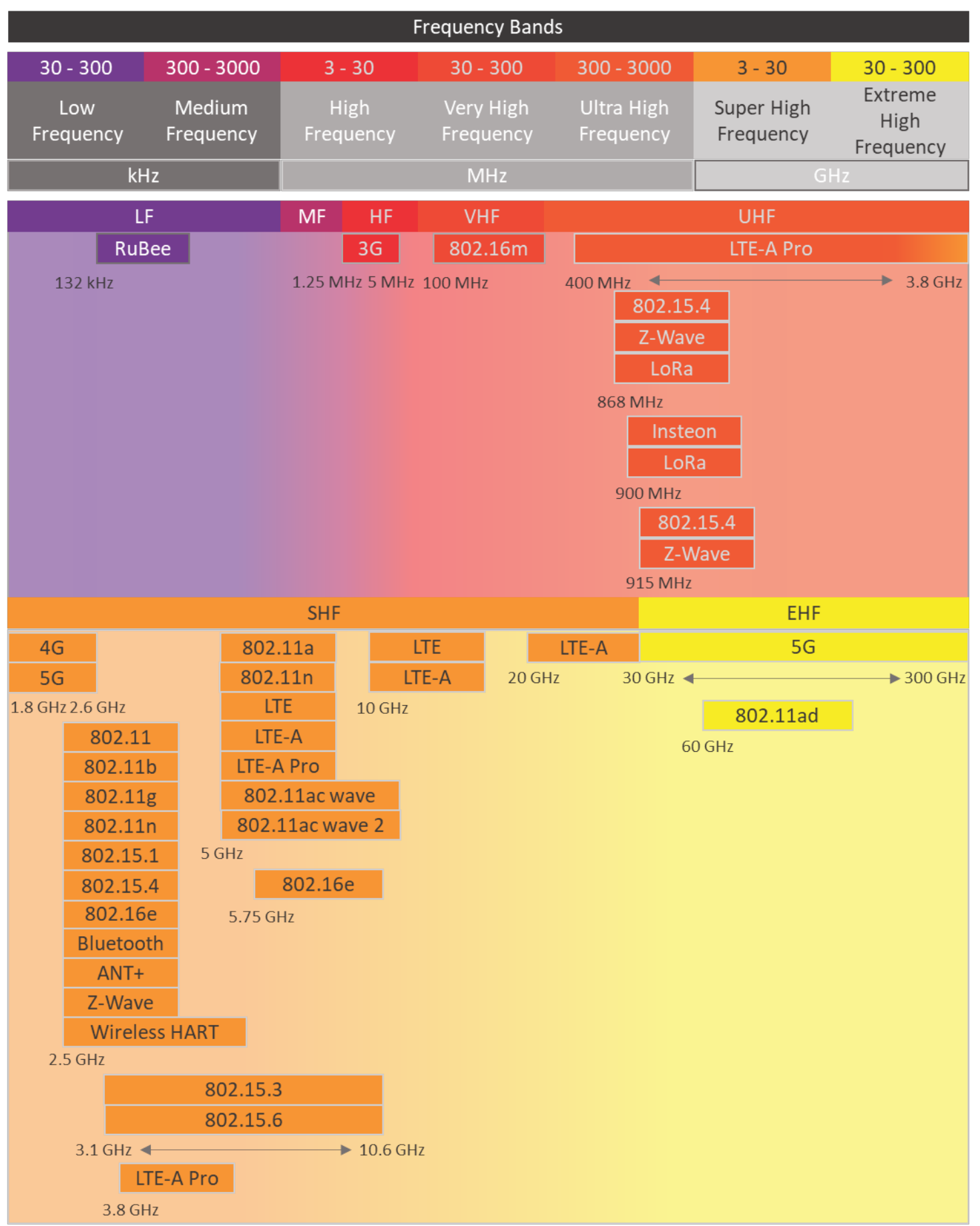

Figure 5. Wireless technologies in the frequency spectrum.

A study of the co-existence between IEEE 802.11 and IEEE 802.16 was performed in [95]. Results show only in the scenario with 0dB energy threshold and high connectivity, IEEE 802.16 technologies are unaffected. Otherwise, IEEE 802.11 and IEEE 802.16 co-existence suffers when utilizing the same channel. The interferences between IEEE 802.11 and IEEE 802.16 result in just a $40 \%$ of available capacity in the simulations performed in [96]. They also propose a coexistence algorithm that increases channel utilization up to $20 \%$ providing fairness among both technologies. Another solution is presented in [97] where authors employ the Common Spectrum Coordination Channel (CSCC) etiquette protocol to 
reduce interference between IEEE 802.11 and IEEE 802.16 technologies sharing the 2,4GHz ISM band. Results also show that CSCC can solve the hidden-receiver problem and improve system throughput.

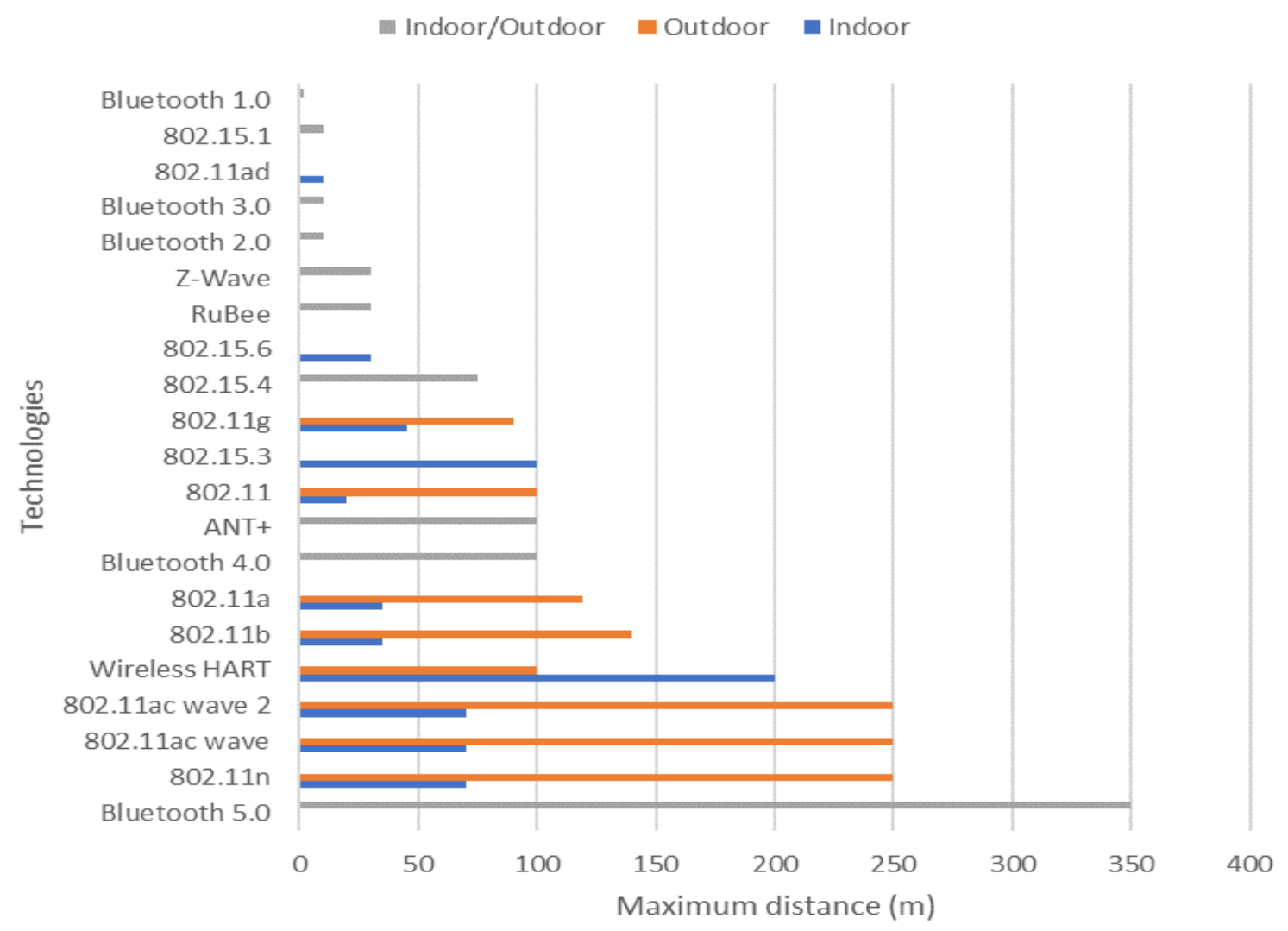

Figure 6. Maximum distance for short and medium ranged technologies.

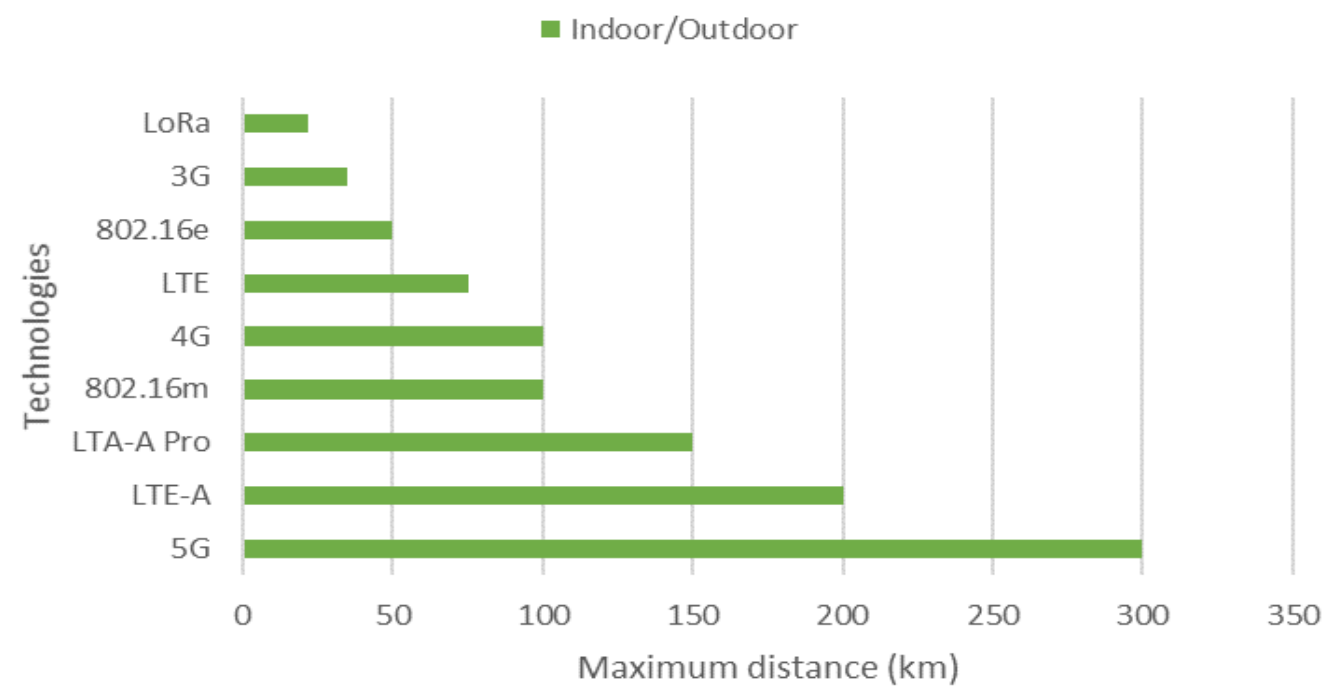

Figure 7. Maximum distance for long-ranged technologies.

As data traffic increases cellular networks are considering employing unlicensed bands to provide multimedia services, specifically the $5 \mathrm{GHz}$ frequency band. However, although this 
band is not as highly used as the 2,4GHz ISM band, LTE-U technologies employing the $5 \mathrm{GHz}$ band may be faced by interferences caused by WiFi. The results provided by [98] show that LTE-U can obtain high throughput for small cell users while allowing WiFi networks to perform well. The coexistence between WiFi and LTE is also studied by [99]. They perform several simulations considering WiFi, Licensed-Assisted Access (LAA), Time Division Duplexing (TDD) and LTE Uplink (LTE-UL). When operating in the same frequency band, results show WiFi has higher performance than LAA. They also conclude that some configurations of LTE TDD and LTE UL can improve WiFi performance at the cost of slightly reducing LAA performance.

\subsection{Power consumption}

WiFi devices can run both on electricity or battery power. Choosing one or the other will depend on the use the device will be given. In domestic environments or companies, it is fairly easy to rely on electricity as it is easily accessible. However, devices such as tablets and portables PCs are preferably employed without being connected to the electricity grid and require consuming less battery. Power consumption on WiFi networks depend on traffic sizes and data rates [100]. Multimedia traffic is bound to deplete battery life quite fast thus services where constant multimedia traffic transmission is required should consider a constant connection to the electricity grid. Although consuming little power is desired whether the devices is connected to the grid or not, some applications may present an acute need for power saving. Access points powered by solar panels allow to transmit information from outdoor locations in an environmentally friendly way [101]. However, weather conditions can present a challenge in maintaining the transmission.

Bluetooth and ZigBee were designed to transmit small quantities of data within a close range. Thus, power consumption is fairly low. Artem Dementryev et al. compare in [102] the energy consumption of Bluetooth low energy (BLE), ZigBee and ANT. Their results show that BLE has the lowest power consumption among the three, followed by ZigBee and ANT. Another comparative study between BLE and ZigBee is performed in [103]. They studied the energy consumption of both network discovery and data transfers and determined that during discovery phase, energy consumption is very similar, being ZigBee slightly higher than Bluetooth. Their results for data transmits show that BLE energy utility is 2.5 times better than that of ZigBee.

As a user, it is easily noticeable that as mobile technologies develop, battery consumption increases. Whether it increases because of the OS, applications or transmission technology, saving battery life is of great importance. A comparison of the power consumption between 2G and 3G is performed in [104]. Results show that 3G consumes more energy for SMS and up to 50\% more for voice services. On the other hand, higher data rates and lower energy consumption is achieved with $3 \mathrm{G}$ for data transmission. After performing some measurements, authors in [105] state that WiFi is more efficient than $3 \mathrm{G}$ regardless of the transfer size. In [106] results show that LTE has higher downlink and uplink throughput than $3 \mathrm{G}$ and WiFi but it is less power efficient than 3G and 23 times less power efficient than WiFi. 


\section{Conclusion and Future Work}

In this paper, we have determined the principal domains that are comprised in a Smart City. They were explained with examples of applications. Moreover, an extensive review on the wireless technologies available nowadays and their evolution has been performed. The characteristics of each technology and their adequacy to each domain has been commented as well. Thus, IEEE 802.11 standards are more suitable for governance, economy, people and infrastructure domains as it is popular for indoor environments. IEEE 802.15 standards are employed for implementations that require low energy consumption and lower data transmissions, for example, in the technology, infrastructure and management dimensions. IEEE 802.16 standards are adequate for the management and technology domain as it provides long range communications. Cellular standards are highly employed in urban environments. However, it is less adequate for the management domain as rural areas may not have the necessary infrastructure for cellular communications. Furthermore, the problems derived from high frequency band occupancy and the coexistence between the different wireless technologies as well as the energy consumption of said technologies have also been discussed.

As a future work, we are planning to develop a QoL assessment system for Smart Cities based on our previous work in [107] and also, employing the knowledge obtained from this paper to choose the best wireless technology in order to establish communication among several devices.

\section{References}

[1] R. Dameri, "Searching for Smart City definition: a comprenhensive proposal”, International Journal of Computers and Technology, Vol. 11, no 5, October 2013, pp. 2544-2551.

[2] EC, European Commission, Leading the way in making Europe's cities smarter, 2013, Frequently asked questions. MEMO/13/1049, http://europa.eu/rapid/press-release_MEMO-13-1049_en.htm (last access October 2017)

[3] F. Russo, C. Rindone and P. Panuccio, "The process of smart city definition at an EU level”, WIT Transactions on Ecology and the Environment, Vol. 191, 2014, pp. 979-989. DOI: https://doi.org/10.2495/SC140832

[4] A. Rghioui, S. Sendra, J. Lloret, A, Oumnad, "Internet of Things for Measuring Human Activities in Ambient Assisted Living and e-Health”, Network Protocols and Algorithms, Vol 8, No 3, 2016, pp. 15-28. DOI: https://doi.org/10.5296/npa.v8i3.10146

[5] J. Lloret, J. Tomas, A. Canovas and L- Parra, “An Integrated IoT Architecture for Smart Metering”, IEEE Communications Magazine, Vol. 54, no 12, December 2016, pp. 50-57. DOI: https://doi.org/10.1109/MCOM.2016.1600647CM

[6] G. P. Hancke, B. de Carvalho e Silva and G. P. Hancke Jr, "The role of advanced sensing 
in smart cities" Sensors, 2012, vol. 13, no 1, p. 393-425. DOI: https://doi.org/ $10.3390 / \mathrm{s} 130100393$

[7] R. Piyare and M. Tazil, "Bluetooth based home automation system using cell phone”, IEEE $15^{\text {th }}$ International Symposium on Consumer Electronics, Singapore, Singapore, 14-17 June 2011, pp. 192-195. DOI: https://doi.org/10.1109/ISCE.2011.5973811

[8] M. F. A. Rasid and B. Woodward, "Bluetooth Telemedicine Processor for Multichannel Biomedical Signal Transmission via Mobile Cellular Networks”, IEEE Transactions on Information Technology In Biomedicine, Vol 9, no 1, March 2005, pp. 35-43. DOI: https://doi.org/10.1109/TITB.2004.840070

[9] J Lloret, A Canovas, S Sendra and L Parra, “A smart communication architecture for ambient assisted living”, IEEE Communications Magazine, Vol. 53, no 1, pp. 26-33, 2015. DOI: https://doi.org/10.1109/MCOM.2015.7010512

[10] J. Lloret, L. Parra, M. Taha and J. Tomás, “An architecture and protocol for smart continuous eHealth monitoring using 5G”, Computer Networks, 2017, In Press. DOI: https://doi.org/10.1016/j.comnet.2017.05.018

[11] P. Neirotti, A. De Marco, A. C. Cagliano, G. Mangano and F. Scorrano, "Current trends in Smart City initiatives: Some stylized facts”, Cities, Vol. 38, 2014, pp. 25-36. DOI: https://doi.org/ 10.1016/j.cities.2013.12.010

[12] S. Alawadhi, A. Aldama-Nalda, H. Chourabi, J. R. Gil-Garcia, S. Leung, S. Mellouli, T. Nam, T. A. Pardo, H. J. Scholl and S. Walker, "Building Understanding of Smart City Initiatives”, Electronic government, 2012, pp. 40-53. DOI: https://doi.org/10.1007/978-3-642-33489-4_4

[13] M: Al-Hader, A. Rodzi, A. R. Sharif and N. Ahmad, "Smart City Components Architecture”, International Conference on Computational Intelligence, Modelling and Simulations, Brno, Czech Republic, 7-9 September 2009, pp. 93-97. DOI: https://doi.org/ 10.1109/CSSim.2009.34

[14] J. Marín, J. Rocher, L. Parra, S. Sendra, J. Lloret and P. V. Mauri, “Autonomous WSN for Lawns Monitoring in Smart Cities”, The 5th International workshop on Big Data and Social Networking Management and Security, Hammamet, Tunisia, Oct 30 - Nov 3, 2017.

[15] L. Parra, S. Sendra, J. Lloret and I. Bosch, "Development of a conductivity sensor for monitoring groundwater resources to optimize water management in smart city environments”, Sensors, Vol. 15, no 9 , 2015, pp. 20990-21015. DOI: https://doi.org/ $10.3390 / \mathrm{s} 150920990$

[16] T. Nam and T. A. Pardo, "Conceptualizing Smart City with Dimensions of Technology, People, and Institutions”, The Proceedings of the 12th Annual International Conference on Digital Government Research, College Park, Maryland, USA, 12-15 June 2011, pp. 282-291. DOI: https://doi.org/ 10.1145/2037556.2037602

[17] Standards Development Working Group, WG802.11 - Wireless LAN Working Group. 
Available online: https://standards.ieee.org/develop/wg/WG802.11.html (accessed on 1210 2017)

[18] IEEE Computer Society. Available online: https:/www.computer.org/web/guest/ (accessed on 1210 2017)

[19] Standards Activities. Available online: https://www.computer.org/web/standards (accessed on 1210 2017)

[20] IEEE 802 LAN/MAN Standards Committee. Available online: http://www.ieee802.org (accessed on 1210 2017)

[21] K.J. Silva Lorraine, Pavana sai.R, Suresh babu.T, Rama krishna.K, Tejavanth Hari.V, "Design of CPW-fed Capacitive CoupledPatch Antenna forWiGig Applications", International Journal Of Engineering And Science, Vol.5, Issue 6 (June 2015), pp 17-23, Issn (e): 2278-4721, Issn (p):2319-6483

[22] M.2003: Multiple gigabit wireless systems in frequencies around $60 \mathrm{GHz}, \mathrm{M} .2003-1$ (01/2015). Available online: https://www.itu.int/rec/R-REC-M.2003/en (accessed on 1210 2017)

[23] S. C. Ergen, “ZigBee/IEEE 802.15.4 Summary”, UC Berkeley, Vol. 10, September 2004, pp. 17.

[24] IEEE Computer Society, "Part 15.1: Wireless medium access control (MAC) and physical layer (PHY) specifications for wireless personal area networks (WPANs)”, 14 June 2005

[25] J. Lee, Y. Su and C. Shen, “A Comparative Study of Wireless Protocols: Bluetooth, UWB, ZigBee and WiFi”, 33rd Annual Conference of the IEEE Industrial Electronics Society (IECON), Taipei, Taiwan, 5-8 November, 2007, pp. 46-51. DOI: https://doi.org/ 10.1109/IECON.2007.4460126

[26] C. Bisdikian, “An Overview of the Bluetooth Wireless Technology”, IEEE Communications Magazine, Vol. 39, no 12, December 2001, pp 86-94. DOI: https://doi.org/ $10.1109 / 35.968817$

[27] E. Ferro and F. Potortì, "Bluetooth and Wi-Fi wireless protocols: A survey and comparison”, IEEE Wireless Communications, Vol. 12, no 1, February 2005, pp. 12-26. DOI: https://doi.org/ 10.1109/MWC.2005.1404569

[28] S. Vyas, U. Chaudhari, V. C. Nandini and B. Thakare, "State of the Art Literature Survey 2015 on Bluetooth", International Journal of Computer Applications, Vol. 131, no 8, December 2015, pp. 7-10. DOI: https://doi.org/ 10.5120/ijca2015907391

[29] S. Darroudi and C. Gomez, "Bluetooth Low Energy Mesh Networks: A Survey”, Sensors, MDPI, Vol. 17, no 7, 22 June 2017, pp. 1467. DOI: https://doi.org/10.3390/s17071467

[30] IEEE Computer Society, "IEEE Standard for High Data Rate Wireless Multi-Media Networks”, 15 May 2016. 
[31] S. C. Ergen, “ZigBee/IEEE 802.15.4 Summary”, UC Berkeley, Vol. 10, September 2004, pp. 17.

[32] K. Mikhaylov, N. Plevritakis and J. Tervonen, "Performance Analyss and Comparison of Bluetooth Low Energy with IEEE 802.15.4 and SimpliciTI”, Journal of Sensor and Actuator Networks, Vol. 2, no 3, August 2013, pp. 589-613. DOI: https://doi.org/ 10.3390/jsan2030589

[33] J. H. Kurunathan, "Study and overview on WBAN under IEEE 802.15.6", U. Porto Journal of Engineering, Vol 1, no 1, 1 October 2015, pp. 11-21.

[34] K. S. Kwak, S. Ullah and N. Ullah, “An overview of IEEE 802.15.6 Standard”, IEEE 3rd International Symposium on Applied Sciences in Biomedical and Communication Technologies, Rome, Italy, 7-10 November 2010, pp. 1-6.

[35] A. Salehi, M. A. Razzaque, I. Tomeo-Reyes and N. Hussain, "IEEE 802.15.6 Standard in Wireless Body Area Networks From a Healthcare Point of View”, The IEEE 22nd Asia-Pacific Conference on Communications, Yogyakarta, Indonesia, 25-27 August 2016, pp. 523-528. DOI: https://doi.org/ 10.1109/APCC.2016.7581523

[36] T. Lennvall, S. Svensson and F. Hekland, “A Comparison of WirelesHART and ZigBee for Industrial Applications”, IEEE International Workshop on Factory Communication Systems, Dresden, Germany, 21-23 May 2008, pp. 85-88. DOI: https:/doi.org/ 10.1109/WFCS.2008.4638746

[37] J. Song, S. Han, A. K. Mok, D. Chen, M. Lucas, M. Nixon and W. Pratt, "WirelessHART: Applying Wireless Technology in Real-Time Industrial Process Control”, IEEE Real-Time and Embedded Technology and Applications Symposium, St. Louis, MO, USA, 22-24 April 2008, pp. 377-386. DOI: https://doi.org/10.1109/RTAS.2008.15

[38] N. Q.Mehmood and R. Culmone, “An ANT+ protocol based health care system”, IEEE 29th International Conference on Advanced Information Networking and Applications Workshops, Gwangju, South Korea, 24-27 March 2015, pp. 193-198. DOI: https://doi.org/10.1109/WAINA.2015.45

[39] R. Belchior, D. Júnior and A. Monteiro, “ANT+ Medical Health Kit for Older Adults”, International Conference on Wireless Mobile Communication and Healthcare, Springer, 2013, pp. 20-29.

[40] X. Yu, X. Xia and X. Chen, "Desing and Application of RuBee-based Telemedicine Data Acquisition System”, 10th IEEE/ACIS International Conference on Computer and Information Scence, Sanya, China, 16-18 May 2011, pp. 365-370. DOI: https://doi.org/10.1109/ICIS.2011.64

[41] T. Wu, J. Wu and W. Weng, "Improvement Security for RuBee Radio-WiMax Mesh Networks", Proceedings of the International Conference on Mobile Technology, Applications and Systems, ACM, 2008, pp. 114. DOI: https://doi.org/10.1145/1506270.1506408

[42] R. Robles and T. Kim, “Applications, Systems and Methods in Smart Home Technology: A Review”, International Journal of Advanced Science and Technology, Vol. 15, February 
2010, pp. 37-48.

[43] B. Fouladi and S. Ghanoum, "Security Evaluation of the Z-wave Wireless Protocol”, Black hat USA, Vol. 24, 2013, pp. 1-2.

[44] E. Puskar and T. A. Aanstoos "An Overview of the Development and Potential Impact of the IEEE 802.16 (WiMAX) Standard”, Report No. NISTIR, Vol. 7473, 2007.

[45] H. L. Vu, S. Chan , L. L. H. Andrew, "Performance Analysis of Best-Effort Service in Saturated IEEE 802.16 Networks”, IEEE Transactions on Vehicular Technology, Vol. 59, No. 1, pp. 460-472, 2010. DOI: https://doi.org/10.1109/TVT.2009.2033191

[46] F. leccese, M. Cagnetti and D. Trinca, “A Smart City Application: A Fully Controlled Street Lighting Isle Based on Raspberry-Pi Card, a ZigBee Sensor Network and WiMAX”, Sensors, Vol. 14, No. 12, pp. 24408-24424, 2014. DOI: https://doi.org/10.3390/s141224408

[47] A. Agarwal and K. Agarwal, "The Next Generation Mobile Wireless Cellular Networks-4G and Beyond", American Journal of Electrical and Electronic Engineering, Vol. 2, No. 3, pp. 92-97, 2014.

[48] S. Su, K. Wong and C. Tang, "Ultra-wideband square planar monopole antenna for IEEE 802.16a operation in the 2-11-GHz band”, Microwave and Optical Technology Letters, Vol. 42, No. 6, pp. 463-466, 2004. DOI: https://doi.org/10.1002/mop.20337

[49] D. Pareit, B. Lannoo, I. Moerman and P. Demeester, "The History of WiMAX: A Complete Survey of the Evolution in Certification and Standardization for IEEE 802.16 and WiMAX", IEEE Communications Surveys and Tutorials, Vol. 14, No. 4, pp. 1183-1211, 2012. DOI: https://doi.org/10.1109/SURV.2011.091511.00129

[50] F. Wang, A. Ghosh, C. Sankaran, P. J. Fleming, F. Hsieh and S. J. Benes, "Mobile WiMAX systems: performance and evolution", IEEE Communications Magazine, Vol. 46, No. 10, pp. 41-49, 2008. DOI: https://doi.org/ 10.1109/MCOM.2008.4644118

[51] S. J. Vaughan-Nichols, "Achieving wireless broadband with WiMax", Computer, Vol. 37, No. 6, pp. 10-13, 2004.

[52] Q. Li, X. E. Lin, J. Zhang and W. Roh, "Advancement of MIMO technology in WiMAX: from IEEE 802.16 d/e/j to 802.16 m", IEEE Communications Magazine, Vol. 47, No. 6, pp. 100-107, 2009. DOI: https://doi.org/ 10.1109/MCOM.2009.5116806

[53] D. Johnston and J. Walker, "Overview of IEEE 802.16 security", IEEE Security \& Privacy, Vol. 2, No. 3, pp. 40-48, 2004. DOI: https://doi.org/10.1109/MSP.2004.20

[54] C. So-In, R. Jain, and A. Tamimi, "Capacity evaluation for IEEE 802.16 e mobile WiMAX", Journal of Computer Systems, Networks, and Communications, pp. 1-12, 2010. DOI: https://doi.org/10.1155/2010/279807

[55] O. Degani, F. Cossoy, S. Shahaf, E. Cohen, V. Kravtsov, O. Sendik, D. Chowdhury, C. D. Hull and S. Ravid, "A 90-nm CMOS power amplifier for 802.16 e (WiMAX) applications." IEEE Transactions on Microwave Theory and Techniques, Vol. 58, No. 5, pp. 1431-1437, 
2010. DOI: https://doi.org/ 10.1109/TMTT.2010.2042906

[56] S. Prakash, V. Sachin, S. Ravi and K. Zubair, "Quality of Service Based Handoff Schemes for WiMAX/WLAN Networks", International Conference of Advance Research and Innovation, New Delhi, India, 2015, pp. 480-482.

[57] T. Cheng, J. C. Wu, F. Yang and J. Leu, " IEEE 802.16e/m energy-efficient sleep-mode operation with delay limitation in multibroadcast services", International Journal of Communication Systems, Vol. 27, No. 1, pp. 45-67, 2014. DOI: https://doi.org/ 10.1002/dac. 2342

[58] Z. U. Rahman, I. ul Haq, S. Ullah, M. I. Ibn Abid and K. A. Shah, "A Survey of Fourth Generation Technologies in Cellular Networks", International Journal of Science Engineering and advance Technology, Vol. 5, No. 1, pp. 75-78, 2017.

[59] V. K. Jatav and V. Singh. "Mobile WiMAX network security threats and solutions: a survey", International Conference on Computer and Communication Technology (ICCCT), Allahabad, India, 26-28 September 2014, pp. 135-140. DOI: https://doi.org/10.1109/ICCCT.2014.7001481

[60] E. Kammoun, F. Zarai, and M.S. Obaidat "Chapter 6-LTE and 5G systems", Smart Cities and Homes, Key Enabling Technologies, pp. 111-129, 2016. DOI: https://doi.org/10.1016/B978-0-12-803454-5.00006-7

[61] J. G. Andrews, S. Buzzi, W. Choi, S. V. Hanly, A. Lozano, A. CK Soong, and J. C. Zhang. "What will 5G be?" IEEE Journal on selected areas in communications, Vol. 32, No. 6, pp. 1065-1082, 2014. DOI: https://doi.org/ 10.1109/JSAC.2014.2328098

[62] H. Wymeersch and A. Eryilmaz, "Chapter 12 - Multiple access control in wireless networks", Academic Press Library in Mobile and Wireless Communications, pp. 435-465, 2016. DOI: https://doi.org/10.1016/B978-0-12-398281-0.00012-0

[63] C. Skianis, "Introducing automated procedures in 3G network planning and optimization, Journal of Systems and Software” , Volume 86, Issue 6, June 2013, Pages 1596-1602. DOI: https://doi.org/10.1016/j.jss.2013.01.072

[64] E. Dahlman, S. Parkvall and J. Skold, “4G: LTE/LTE-Advanced for Mobile Broadband”, 1st Edition, Academic press, 2013.

[65] W. Jung and Y. Kwon, "Differences between LTE and 3G service customers: Business and policy implication”, Telematics and Informatics, Vol. 32, no. 4, pp. 667-680, 2015. DOI: https://doi.org/ 10.1016/j.tele.2015.03.001

[66] S. Ahmadi, "LTE-Advanced: a practical systems approach to understanding 3GPP LTE releases 10 and 11 radio access technologies”, Academic Press, 2013.

[67] H. Ji, Y. Kim, J. Lee, E. Onggosanusi, Y. Nam, J. Zhang, B. Lee and B. Shim, “Overview of full-dimension MIMO in LTE-advanced pro”, IEEE Communications Magazine, Vol. 55, 
No. 2, pp.176-184, 2016.

[68] A. Haidine, and S. El Hassani, "LTE-a pro (4.5 G) as pre-phase for 5G deployment: closing the gap between technical requirements and network performance", International Conference on Advanced Communication Systems and Information Security (ACOSIS), Marrakesh, Morocco, 17-19 October 2016, pp. 1-7. DOI: https://doi.org/10.1109/ACOSIS.2016.7843933

[69] R. S. Sinha, Y. Wei and S. Hwang, “A survey on LPWA technology: LoRa and NB-IoT”, ICT Express, Vol. 3, No. 1, pp. 14-21, March 2017. DOI: https://doi.org/ 10.1016/j.icte.2017.03.004

[70] A. Augustin, J. Yi, T. Clausen and W. M. Townsley, “A Study of LoRa: Long Range \& Los Power Networks for the Internet of Things”, SENSORS, Vol. 16, No. 9, p. 1466, 2016. DOI: https://doi.org/10.3390/s16091466

[71] A. Zanella, N. Bui, A. Castellani, L. Vangelista and M. Zorzi, "Internet of things for Smart Cities”, IEEE Internet of Things Journal, Vol. 1, No. 1, pp. 22-32, February 2014. DOI: https://doi.org/ 10.1109/JIOT.2014.2306328

[72] E. Khorov, A. Lyakhov, A. Krotov and A. Guschin, “A survey on IEEE 802.11ah: An enabling networking technology for smart cities”, Computer communications, Vol. 58, pp. 53-69, 2015. DOI: https://doi.org/ 10.1016/j.comcom.2014.08.008

[73] M. Centenaro, L. Vangelista, A. Zanella and M. Zorzi, "Long-Range Communications in Unlicensed Bands: The Rising Stars in the IoT and Smart City Scenarios”, IEEE Wireless Communications, Vol. 23, No. 5, pp. 60-67, October 2016. DOI: https://doi.org/ 10.1109/MWC.2016.7721743

[74] M. Castro, A. J. Jara and A. F. G. Skarmeta, "Smart Lighting solutions for Smart Cities”, 27th International Conference on Advanced Information Networking and Applications Workshops, Barcelona, Spain, 25-28 March 2013, pp. 1374-1379. DOI: https://doi.org/ 10.1109/WAINA.2013.254

[75] Z. Ji, I. Ganchev, M. O’Droma, L. Zhao and X. Zhang, “A Cloud -Based Car Parking Middleware for IoT-Based Smart Cities: Design and Implementation”, Sensors, Vol. 14, pp. 22372-22393, 2014.

[76] M. S. Jamil, M. A. Jamil, A. Mazhar, A. Ikram, A. Ahmed and U. Munawar, "Smart Environment Monitoring System by employing Wireless Sensor Networks on Vehicles For Pollution Free Smart Cities”, Procedia Engineering, Vol. 107, pp. 480-484, 2015. DOI: https://doi.org/ 10.1016/j.proeng.2015.06.106

[77] Y. Chen and D. Han, "Water quality monitoring in smart city: A pilot project", Automation in Construction, Vol. 89, pp. 307-316, 2018.

[78] K. Abas, K. Obraczka and L. Miller, "Solar-powered, wireless smart camera network: An IoT solution for outdoor video monitoring”, Computer Communications, Vol. 118, pp. 
217-233, 2018.

[79] I. Yaqoob, I. Abaker, T. Hashem, Y. Mehmood, A. Gani, S. Mokhtar and S. Guizani, "Enabling Communication Technologies for Smart Cities”, IEEE Communications Magazine, January 2017, pp. 112-120. DOI: https://doi.org/ 10.1109/MCOM.2017.1600232CM

[80] S. Sendra, M. Garcia, C. Turro and J. Lloret, "WLAN IEEE 802.11 a/b/g/n Indoor Coverage and Interference Performance Study", International Journal on Advances in Networks and Services, Vol. 4, no 1, pp. 209-222, 2011. DOI: https://doi.org/ 10.1109/ICWMC.2010.46

[81] S. Sendra, P. Fernandez, C. Turro and J. Lloret, "IEEE 802.11 a/b/g/n Indoor Coverage and Performance Comparison”, The Sixth International Conference on Wireless and Mobile Communications. ICWMC 2010, Valencia, Spain, 20-25 September 2010, pp. 185-190. DOI: https://doi.org/ 10.1109/ICWMC.2010.46

[82] Bluetooth core specification v 5.0, Bluetooth SIG Propietary.

[83] M. Chen, S. Gonzalez and A. Vasilakos, "Body Area Networks: A survey”, Mobile Networks and Applications, Springer, Vol 16, no 2, 2011, pp. 171-193.

[84] D. Chen, M. Nixon and A. Mok, "Why WirelessHART”, WirelessHART TM, Springer, 2010, pp. 195-199.

[85] G. Zhou, J. A. Stankovic and S. H. Son, "Crowded spectrum in wireless sensor networks” IEEE Embedded Network Sensors, vol. 6, 2006.

[86] J. Hauer, V. Handziski and A. Wolisz, "Experimental Study of the Impact of WLAN Interference on IEEE 802.15.4 Body Area Networks", Proceedings of the $6^{\text {th }}$ European Conference on Wireless Sensir Networks (EWSN), Cork, Ireland, 11-13 February 2009, pp. 17-32.

[87] M. Matinmikko, M. Mustonen, M. Höyhtyä, T. Rauma, H. Sarvanko and A. Mämmelä, "Distributed and Directional Spectrum Occupancy Measurements in the 2,4 GHz ISM band", $7^{\text {th }}$ International Symposium on Wireless Communication Systems (ISWCS), York, UK, 19-22 September 2010, pp. 976-980. DOI: https://doi.org/ 10.1109/ISWCS.2010.5624366

[88] J. Xing and Y. Zhu, “A survey on body Area Network”, IEEE $5^{\text {th }}$ International Conference on Wireless Communications, Networking and Mobile Computing, 2009, pp. 1-4. DOI: https://doi.org/10.1109/WICOM.2009.5302579

[89] N. Golmie, N. Chevrollier and O. Rebala, "Bluetooth and WLAN Coexistence: Challenges and Solutions”, IEEE Wireless Communications, Vol. 10, no 6, December 2003, pp. 22-29. DOI: https://doi.org/10.1109/MWC.2003.1265849

[90] S. Y. Shin, H. S. Park, S. H. Choi and W. H. Kwon, "Packet error rate analysis of ZigBee Under WLAN and Bluetooth Interferences”, IEEE Transactions on Wireless Communications, Vol. 6, no 8, August 2007, pp. 2825- 2830. DOI: https://doi.org/ 10.1109/MWC.2003.1265849 
[91] R. Natarajan, P. Zand and M. Nabi, “Analysis of Coexistence between IEEE 802.15.1, BLE and IEEE 802.11 in the $2.4 \mathrm{GHz}$ ISM Band", $42^{\text {nd }}$ Annual Conference of the IEEE Industrial Electronics Society, Florence, Italy, 23-26 October 2016, pp. 6025-6032. DOI: https://doi.org/ 10.1109/IECON.2016.7793984

[92] M. Petrova, J. Riihijärvi,P. Mähönen and S. Labella, "Performance Study of IEEE 802.15.4 Using Measurements and Simulations”, IEEE Wireless Communications and Networking Conference, Las Vegas, USA, 3-6 April 2006, pp. 487-492. DOI: https://doi.org/ 0.1109/WCNC.2006.1683512

[93] C. Won, J. Youn, H. Ali, H. Sharif and J. Deogun, “Adaptive Radio Channel Allocation for Supporting Coexistence of 802.15.4 and 802.11b”, IEEE 62 ${ }^{\text {nd }}$ Vehicular Technology Conference, Dallas, USA, 25-28 September 2005, pp. 2522-2526. DOI: https:/doi.org/ 10.1109/VETECF.2005.1559004

[94] R. Diab, G. Chalhoub and M. Misson, “Overview on multi-channel communications in wireless sensor networks”, Network Protocols and Algorithms, 2013, vol. 5, no 3, p. 112-135.

[95] N. J. Thomas, M. J. Willis and K. H. Craig, “Analysis of Co-existence between 802.11 and IEEE 802.16 Systems”, $3^{\text {rd }}$ Annual IEEE Communications Society on Sensor and Ad Hoc Communications and Networks, Reston, VA, USA, 28 September 2006, pp. 615-620. DOI: https://doi.org/ 10.1109/SAHCN.2006.288520

[96] M. M. Siddique, B. Wenning, C. Görg and M. Muehleisen, "Spectrum Sharing between IEEE 802.16 and IEEE 802.11 based Wireless Networks”, IEEE International Symposium on a World of Wireless Mobile and Multimedia Networks (WoWMoM), Montrreal, QC, Canada, 14-17 June 2010, pp. 1-6. DOI: https://doi.org/ 10.1109/WOWMOM.2010.5534964

[97] X. Jing and D. Raychaudhuri, "Spectrum Co-existence of IEEE 802.11b and 802.16a Networks using the CSCC Etiquette Protocol”, First IEEE International Symposium on New Frontiers in Dynamic Spectrum Access Networks (DySPAN), Baltimore, MD, USA, 8-11 November 2005, pp. 243-250. DOI: https://doi.org/ 10.1109/DYSPAN.2005.1542640

[98] R. Zhang, M. Wang, L. X. Cai, Z. Zheng, X. She and L. Xie, “LTE-Unlicensed: The future of Spectrum Aggregation for Cellular Networks”, IEEE Wireless Communications, Vol. 22, no 3, June 2015, pp. 150-159. DOI: https://doi.org/ 10.1109/MWC.2015.7143339

[99] N. Rupasinghe and I. Güvenç, "Licensed-Assisted Access for WiFi-LTE Coexistence in the Unlicensed Spectrum”, Globecom Workshops, Austin, TX, USA, 8-12 December 2014, pp. 894-899. DOI: https://doi.org/10.1109/GLOCOMW.2014.7063546

[100] K. Gomez, R. Riggio, T. Rasheed, D. Miorandi, I. Chlamtac and F. Granelli, “Analysing the Energy Consumption behavior of WiFi Networks", IEEE Online Conference on Green Communications, New York, USA, 26-29 September 2011, pp. 98-104. DOI: https://doi.org/ 10.1109/GreenCom.2011.6082515

[101] T. D. Todd, A. A. Sayegh, M. N. Smadi and D. Zhao, “The Need for Access Point Power Saving in Solar Powered WLAN Mesh Networks”, IEEE Networks, Vol. 22, no 3, 
May-June 2008, pp. 4-10. DOI: https://doi.org/ 10.1109/MNET.2008.4519963

[102] A. Dementyev, S. Hodes, S. Taylor and J. Smith, "Power consumption Analysis of Bluetooth Low Energy, ZigBee and ANT Sensor Nodes in a Cyclic Sleep Scenario”, IEEE International Wireless Symposium, Beijing, China, 14-18 April 2013, pp. 1-4. https://doi.org/ 10.1109/IEEE-IWS.2013.6616827

[103] M. Siekkinen, M. Hiienkari, J. K. Nurminen and J. Nieminen, "How Low Energy is Bluetooth Low Energy? Comparative Measurements with ZigBee/802.15.4”, IEEE Wireless Communications and Networking Conference Workshops, Paris, France, 1 April 2012, pp. 232-237. DOI: https://doi.org/ 10.1109/WCNCW.2012.6215496

[104] G. P. Perrucci, F. H. P. Fitzek, G. Sasso, W. Kellerer and J. Widmer, “On the Impat of 2G and 3G Network Usage for Mobile Phones' Battery Life”, European Wireless Conference, Aalborg, Denmark, 17-20 May 2009, pp. 255-259. DOI: https://doi.org/ 10.1109/EW.2009.5357972

[105] N. Balasurbramanian, A. Balasubramanian and Arun Venkataramani, "Energy Consumption in Mobile Phones: A Measurement Study and Implications for Network Applications”, Proceedings of the $9^{\text {th }}$ ACM SIGCOMM conference on Internet measurement, Chicago, Illinois, USA, 4-6 November 2009, pp. 280-293. DOI: https://doi.org/ 10.1109/IWCMC.2013.6583599

[106] J. Huang, F. Qian, A. Gerber, Z. M. Mao, S. Sen and O. Spatscheck, “A close Examination of Performance and Power Charasteristics of 4G LTE Networks”, Proceedings of the $10^{\text {th }}$ international conference on Mobilesystems, applications and services, Low Wood Bay, UK, 25-29 June 2012, pp. 225-238.

[107] R. Laquesta, L. Garcia, I. Garcia-Magarino and J. Lloret, “System to Recommend the Best Place to Life Based on Wellness State of the User Employing the Heart Rate Variability”, IEEE Access, Vol. 5, pp. 10594-10604, May 2017. DOI:

https://doi.org/10.1109/ACCESS.2017.2702107

\section{Copyright Disclaimer}

Copyright reserved by the author(s).

This article is an open-access article distributed under the terms and conditions of the Creative Commons Attribution license (http://creativecommons.org/licenses/by/3.0/). 